\title{
Building energy simulation: challenges and opportunities
}

\author{
Jan Hensen
}




\section{Building energy simulation: challenges and opportunities}

Jan Hensen

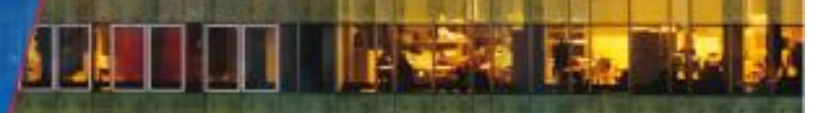

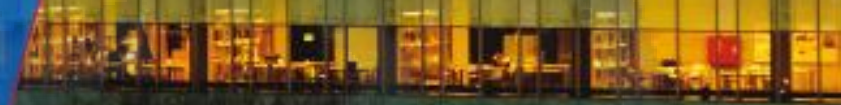

mancasang or
o context
o building simulation
○ quality assurance
o conclusions

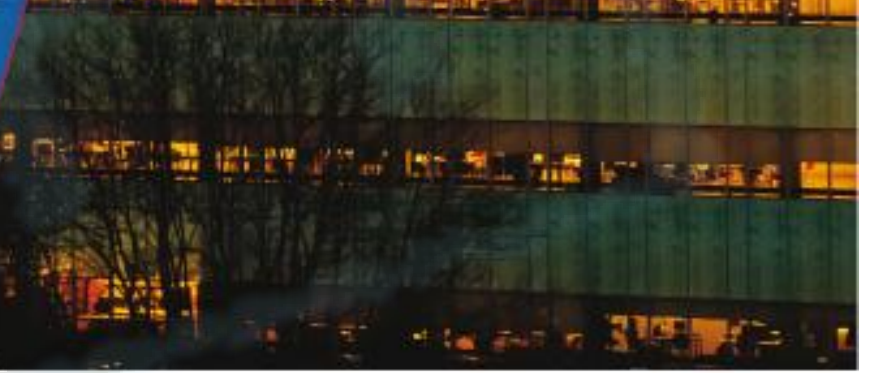

in

TU/e Techische univesistert

Eindhoven

University of Technology

Where innovation starts 


\section{Context - building energy use}

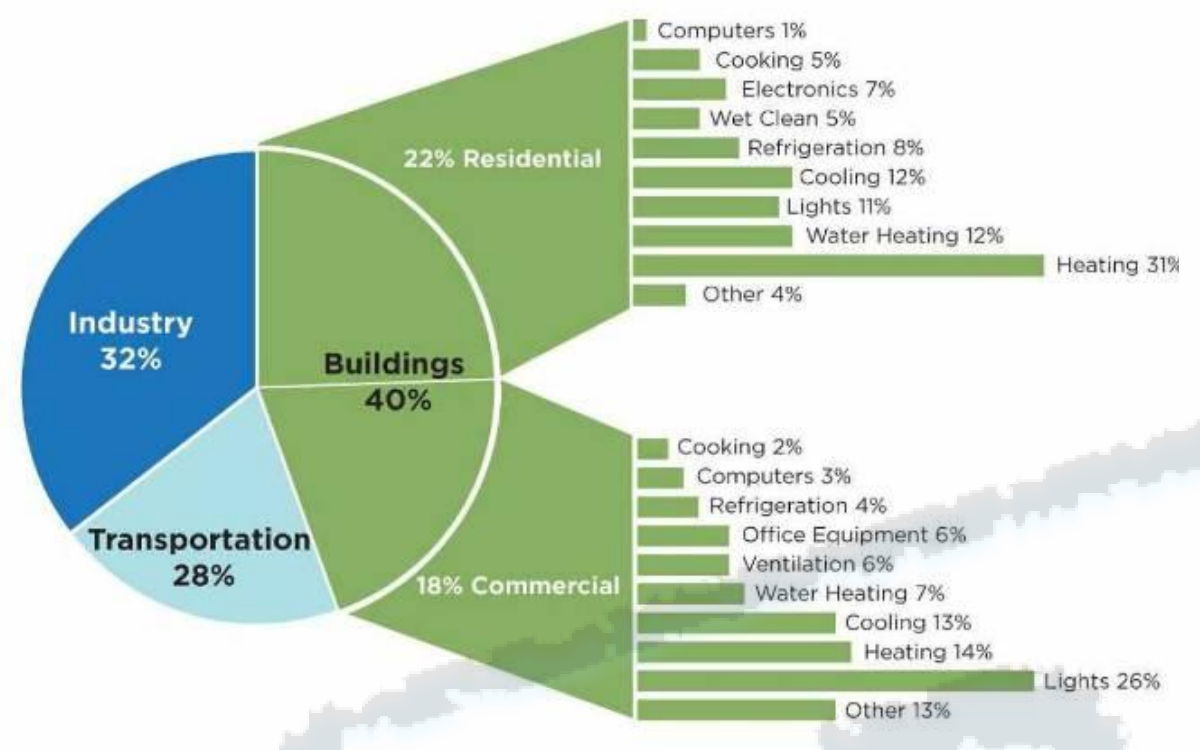

Figure 1. Energy Consumption in the United States

Source: 2007 DOE Buildings Energy Data Book, Tables 1.1.3, 1.2.3, 1.3.3

\section{Energy Demand}

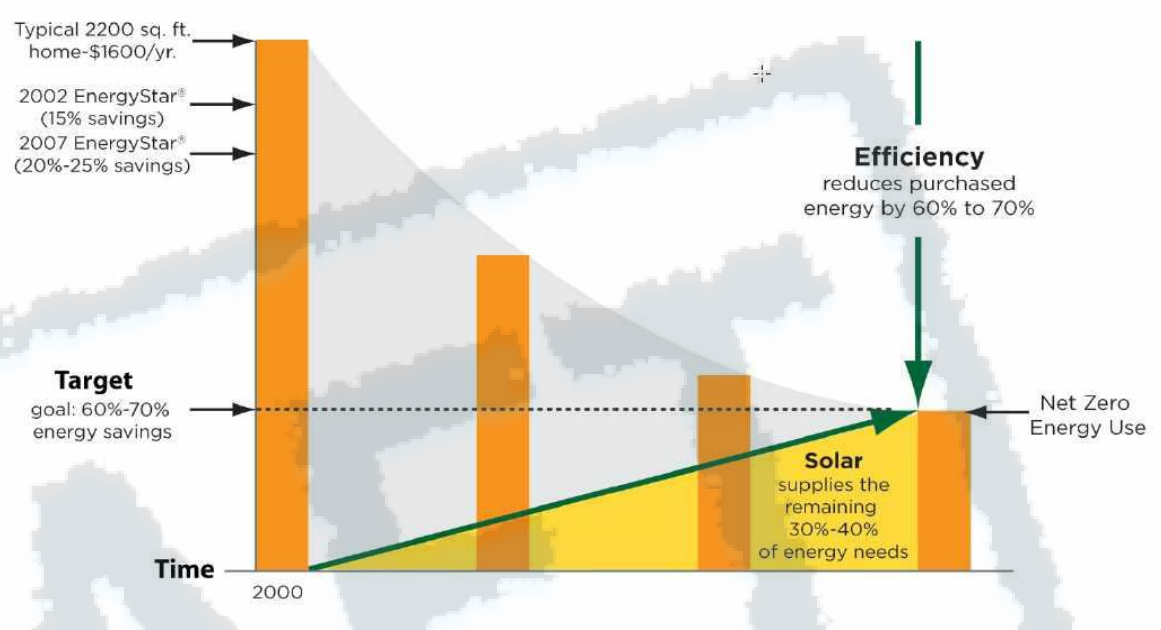

Figure 3. Approach for Achieving Net-Zero Energy Buildings

Federal R\&D Agenda for Net-Zero Energy, High-Performance Green Buildings Report

\section{currently buildings:}

a consume $\sim 37 \%$ world energy

- exploit $\sim 40 \%$ of world resources

- produce $\sim 40 \%$ of world waste 


\section{Context - indoor environment quality}

- Increasing comfort demands

- IEQ $<$ productivitw (arnwinn awarangss)

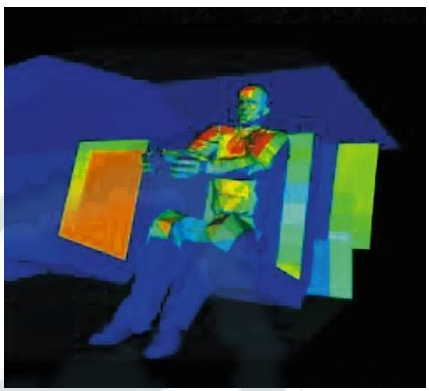

www.automotiveworld.com

Energy costs only a

- IEQ $\gg$ health (re are dominant. small portion of total costs. Personnel costs

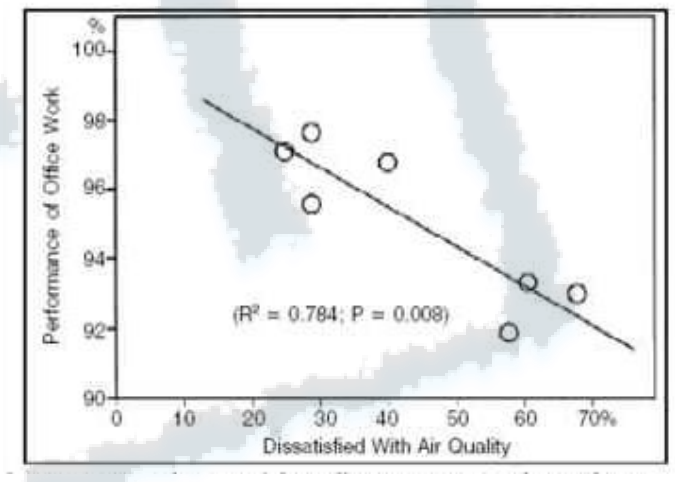

Economic impact:

$€ \quad$ energy

$€ € \quad$ productivity

$€ € €$ health

Wargocki, P 2002 "Making the Case For IAQ", ASHRAE IAQ Applications

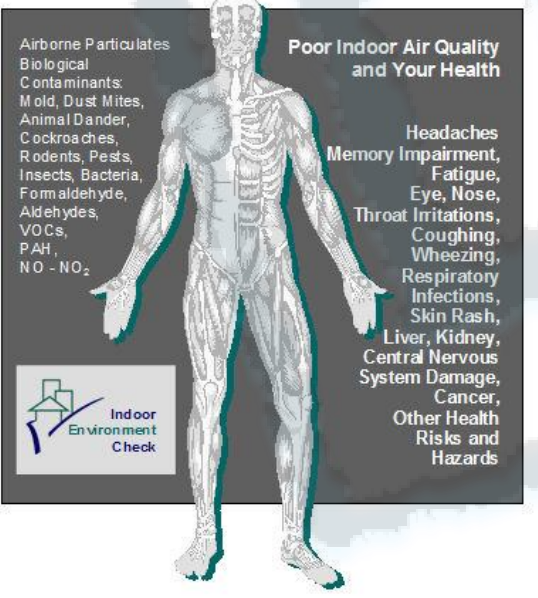

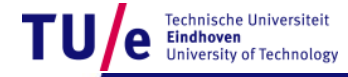


context $>$ building simulation $>$ EPBD $>$ EPBD + simulation $>$ conclusions $>$

\section{Context - general building "issues"}

- Buildings need to be flexible (organizations change)

- Building systems need to be robust

- Buildings are complex
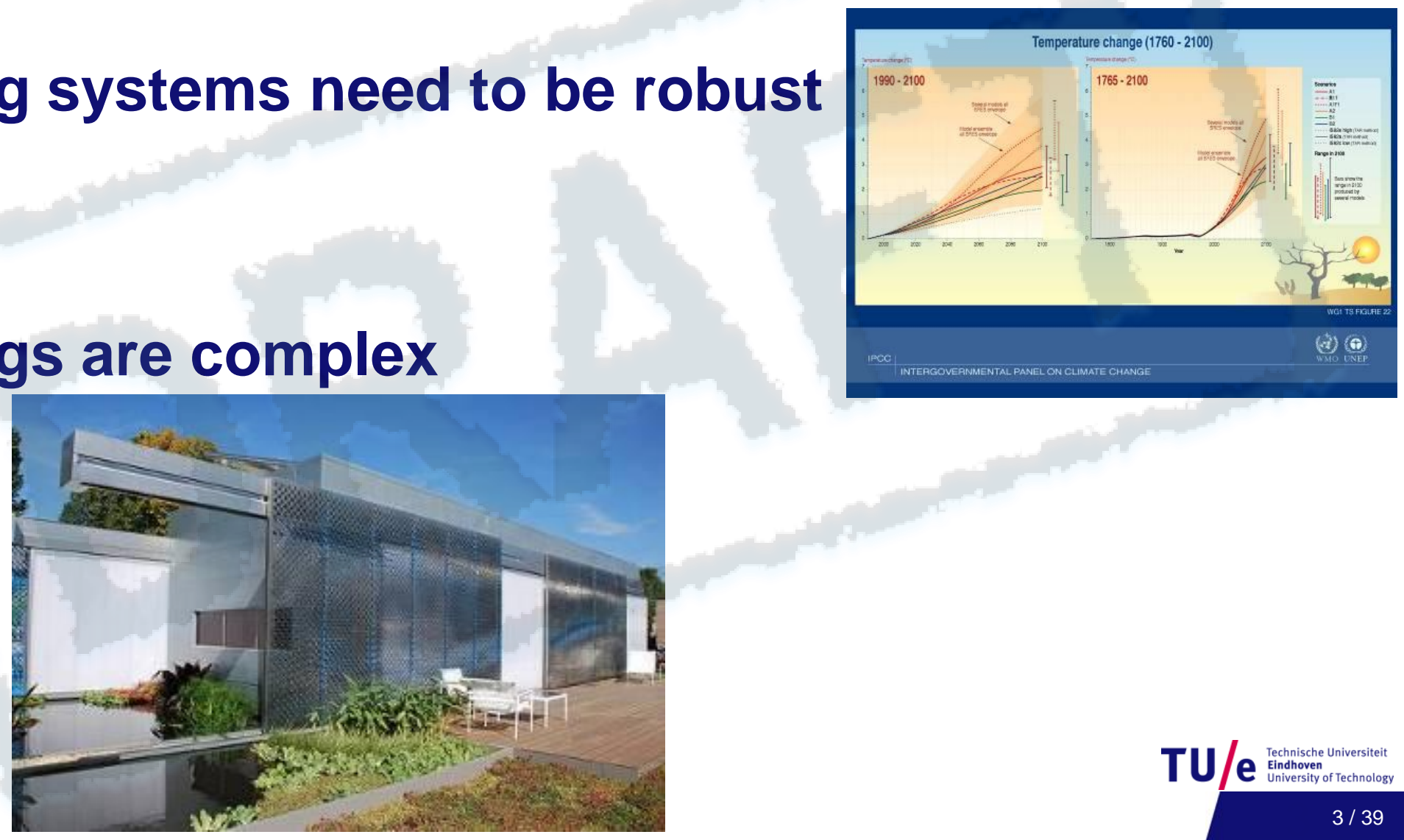


\section{$>$ context $>$ building simulation $>$ EPBD $>$ EPBD + simulation $>$ conclusions $>$ \\ Green design guidance / regulation}

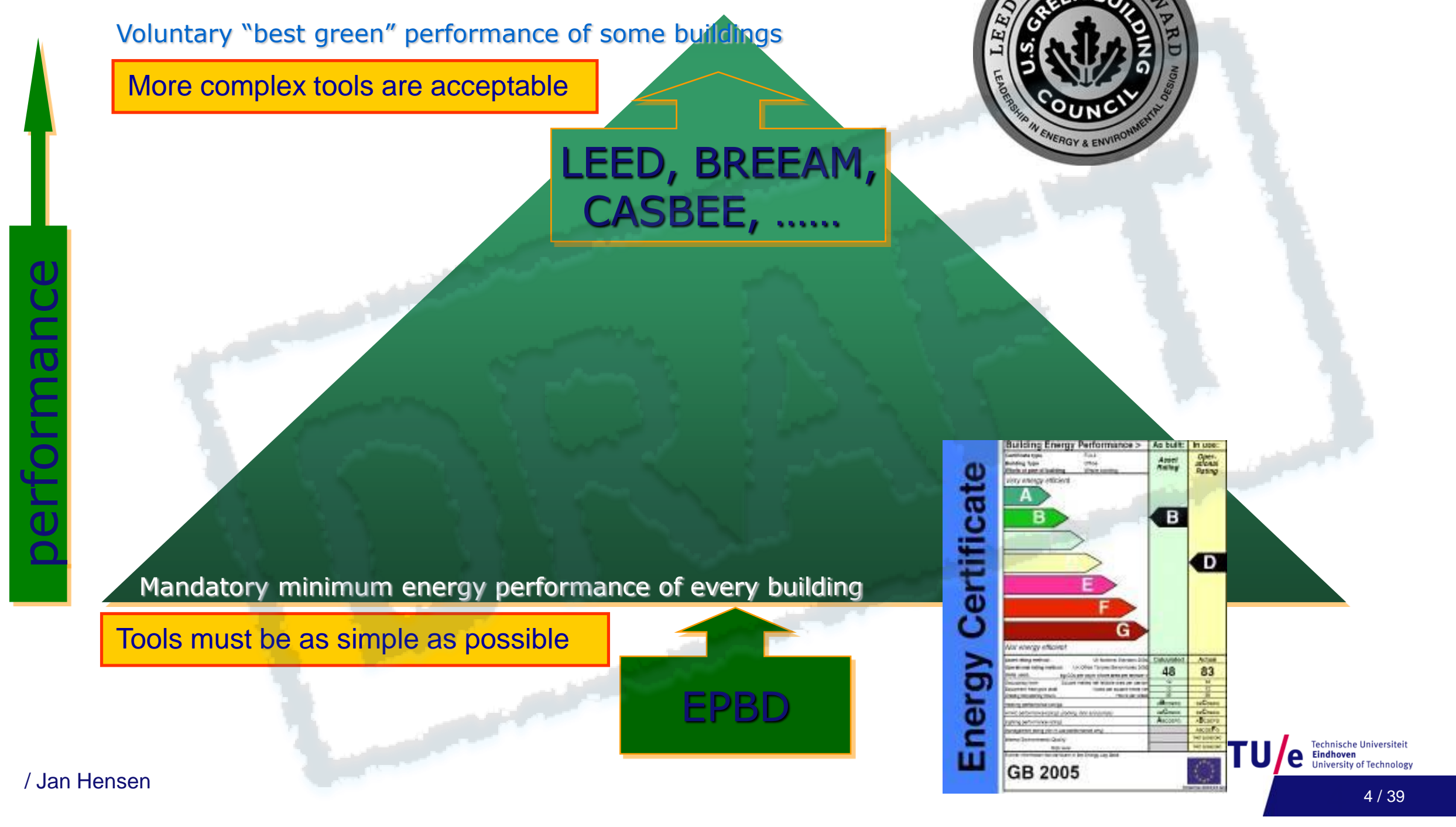




\section{LEED buildings perform better than other buildings on average}

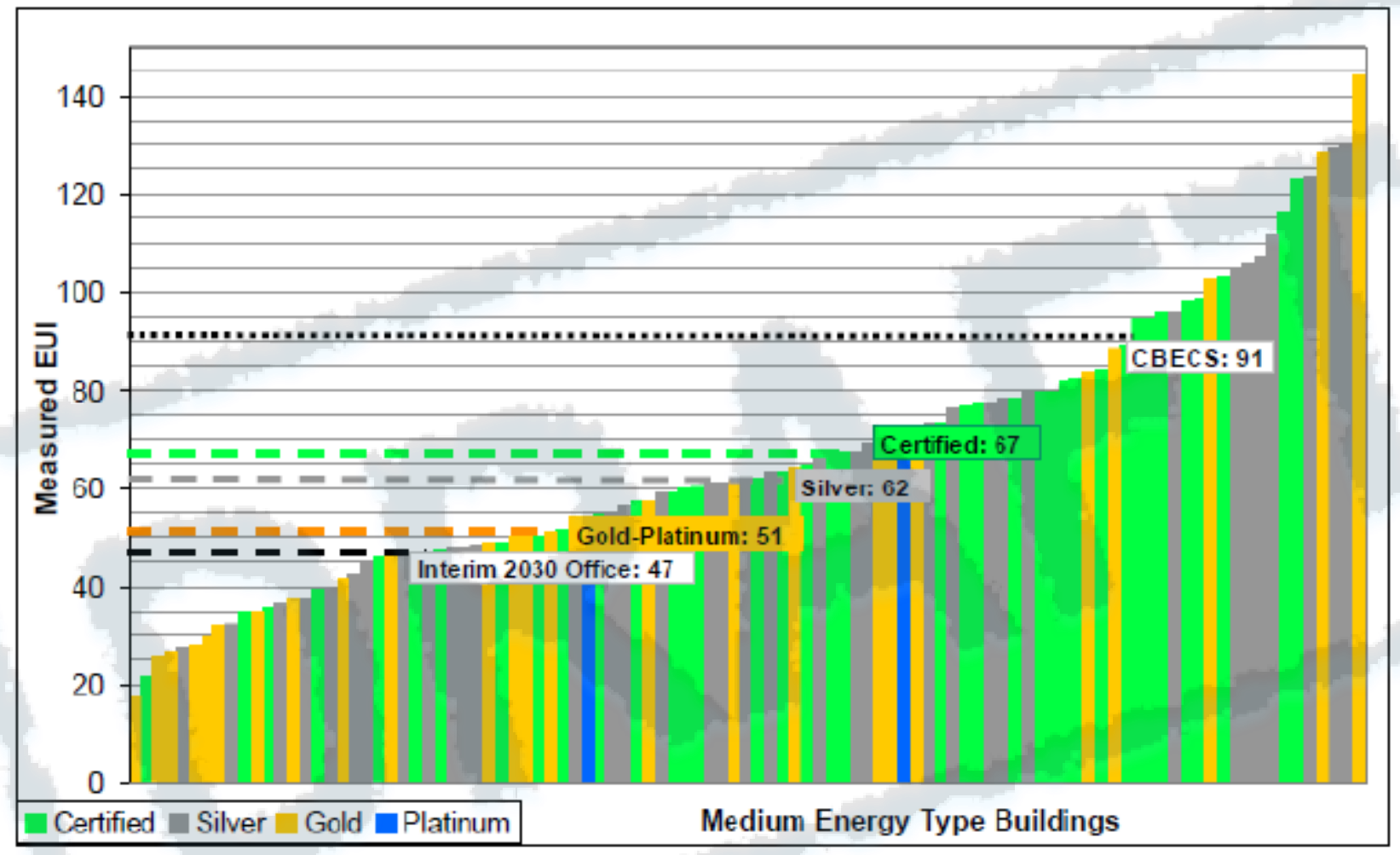

Figure 9: EUIs (kBtu/sf) for Medium Energy Buildings, with Medians by RatingLevel

Turner, C. and M. Frankel. 2008. Energy Performance of LEED ${ }^{\oplus}$ for New Construction Buildings. New Buildings Institute 


\section{...but many perform much worse than predicted}

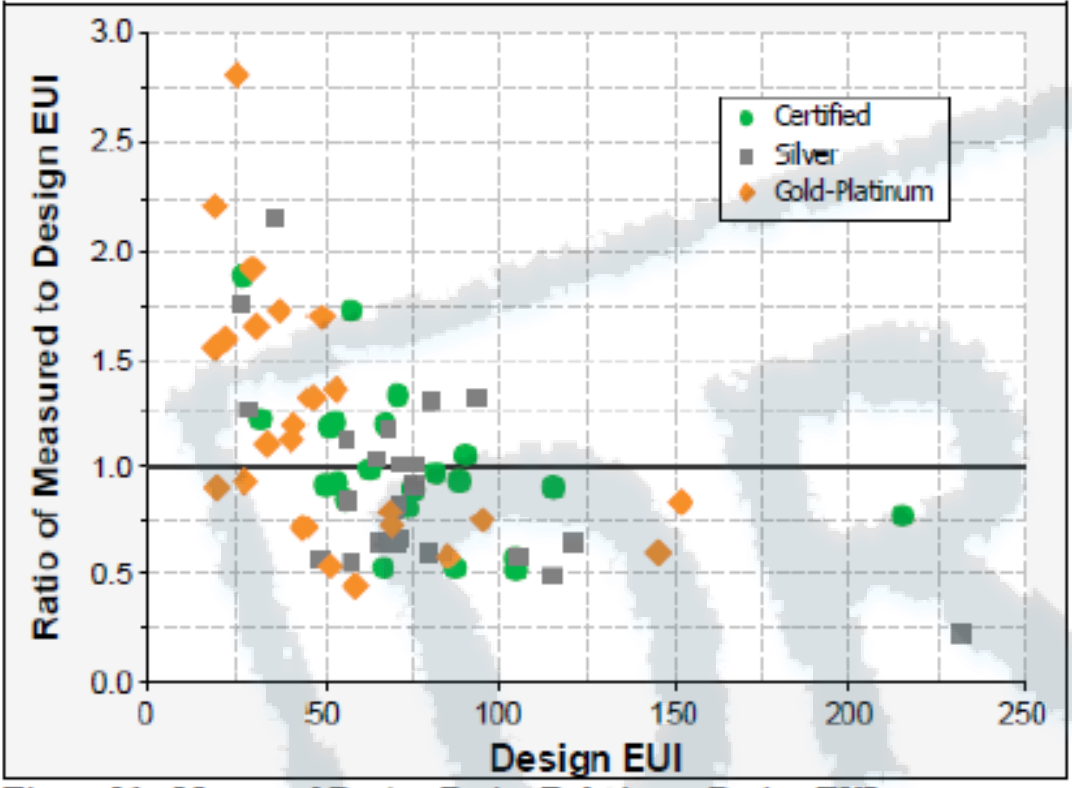

Figure 19: Measured/Design Ratios Relative to Design EUI

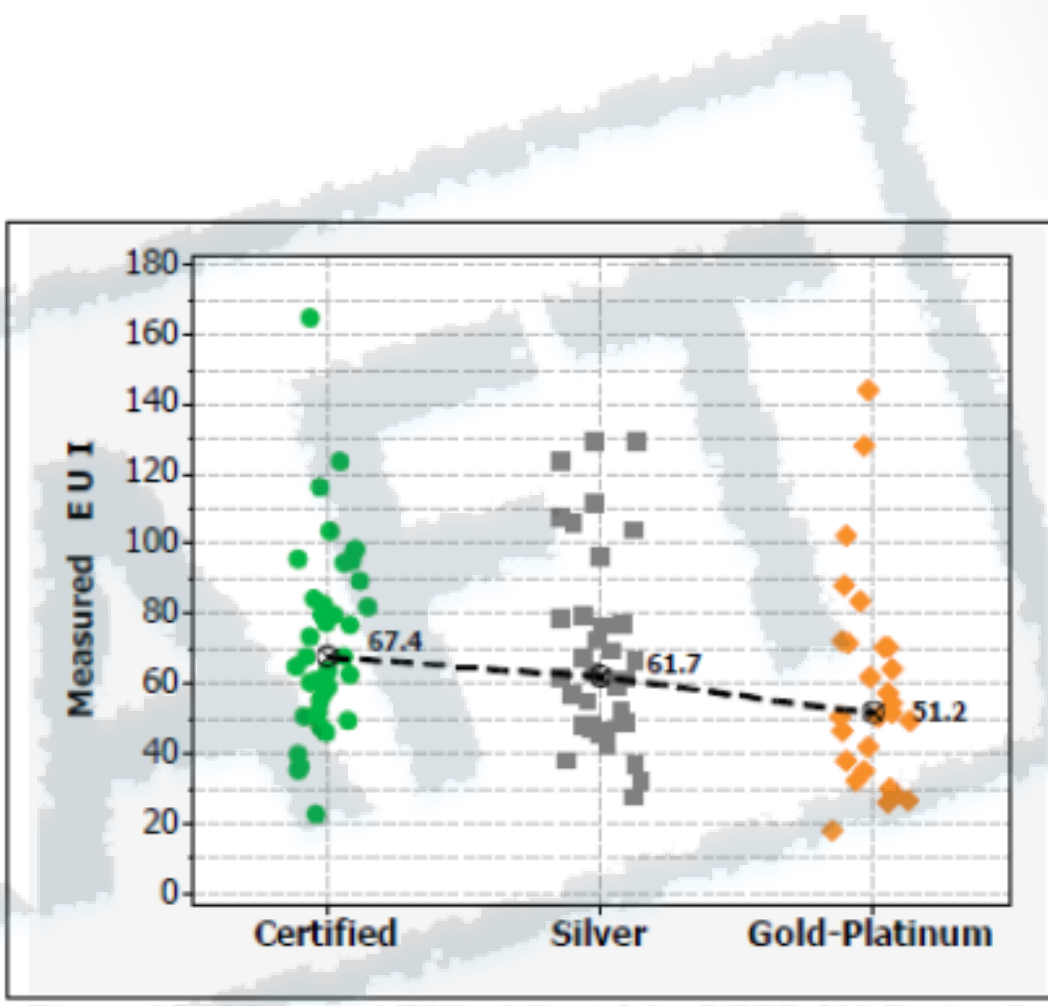

Figure 11: Measured EUIs (kBtu/sf) by LEED-NC Rating Level

Turner, C. and M. Frankel. 2008. Energy Performance of LEED ${ }^{\ominus}$ for New Construction Buildings. New Buildings Institute 


\section{...and some perform worse than code minimum}

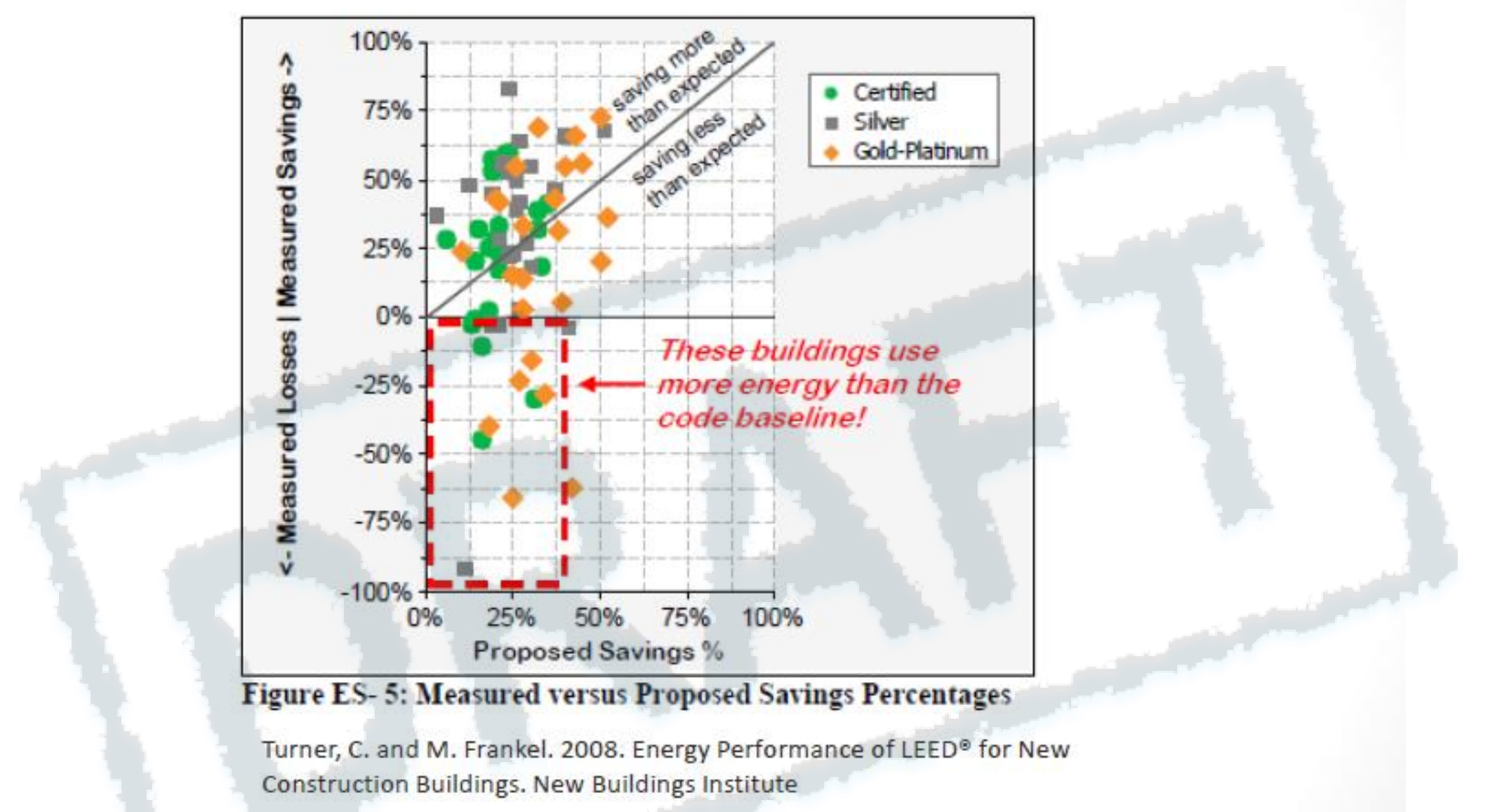

Design standards, codes, and rating systems may be necessary, but they are not sufficient 


\section{Issue - real energy use change}

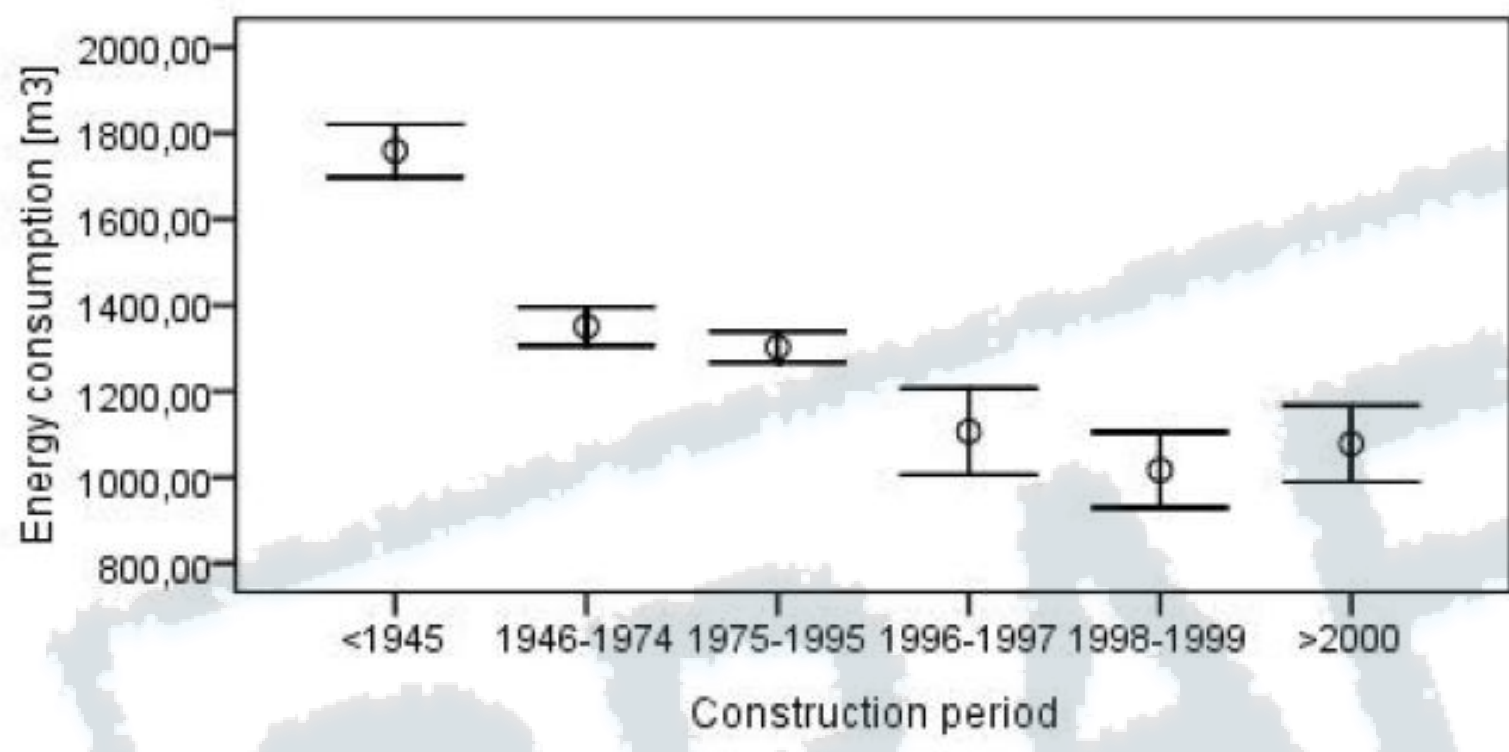

(Source, WoON database, www.VROM.nl)

Figure 4: Mean and $95 \%$ confidence interval for energy consumption per construction period 


\section{Issues - real energy use prediction}

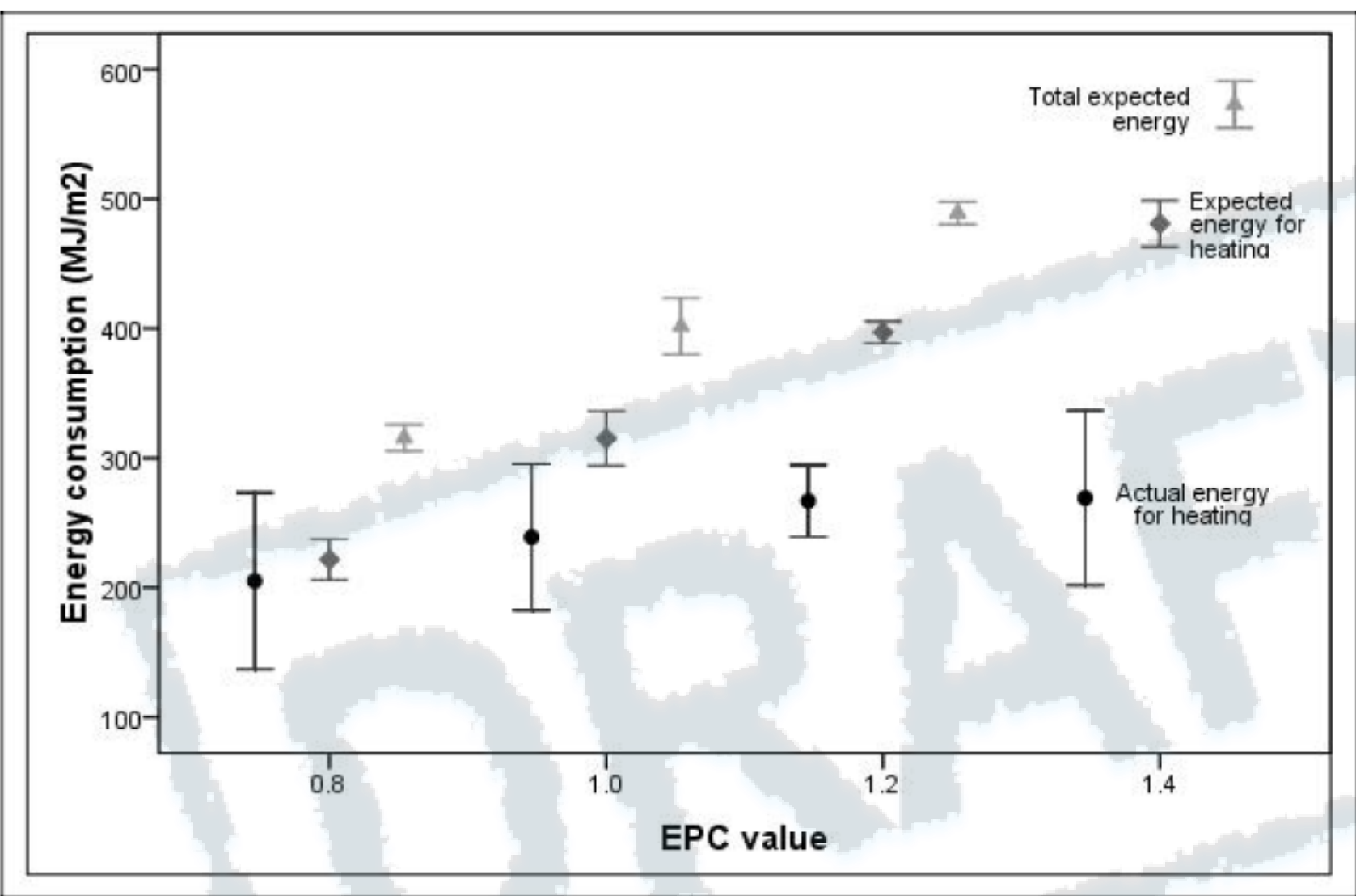

Figure 5 Mean and $95 \%$ confidence interval for the actual energy consumption (MJ/m2), total expected energy $(\mathrm{MJ} / \mathrm{m} 2)$ and expected energy for heating $(\mathrm{MJ} / \mathrm{m} 2)$ per EPC value 


\section{Issue - many existing buildings}

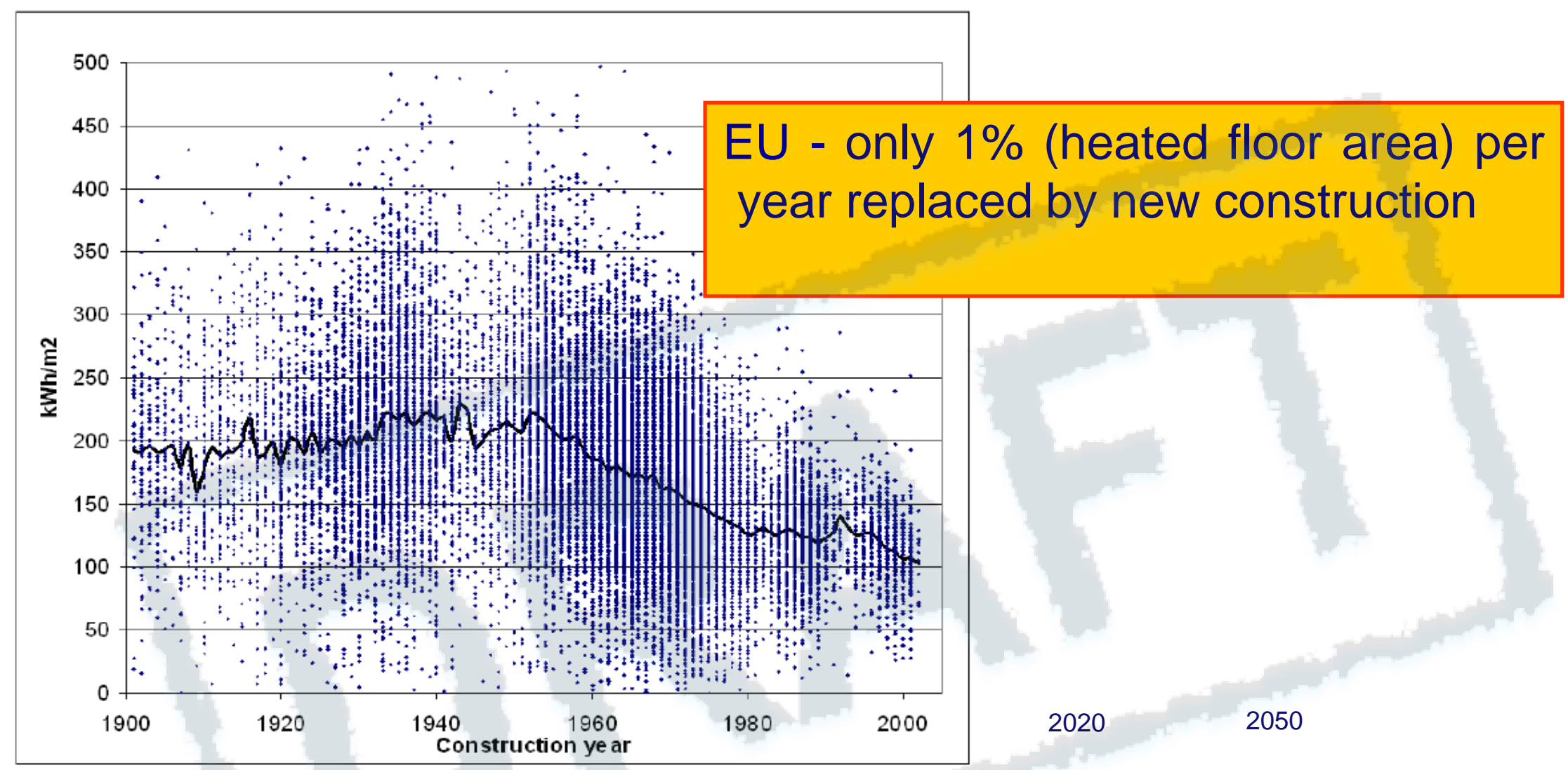

Figure 2 Yearly natural gas consumption $\mathrm{kWh} / \mathrm{m}^{2}$ in 2003 for Danish single-family houses related to construction year and the median. The solid line is the locus of the medians of all the individual observations for each year and the dots are the individual observations 


\section{Traditional tools}

- mono-disciplinary

- solution oriented

- narrow scope

- static

- extreme conditions

- analytical methods (exact solution of very simplified model of reality)

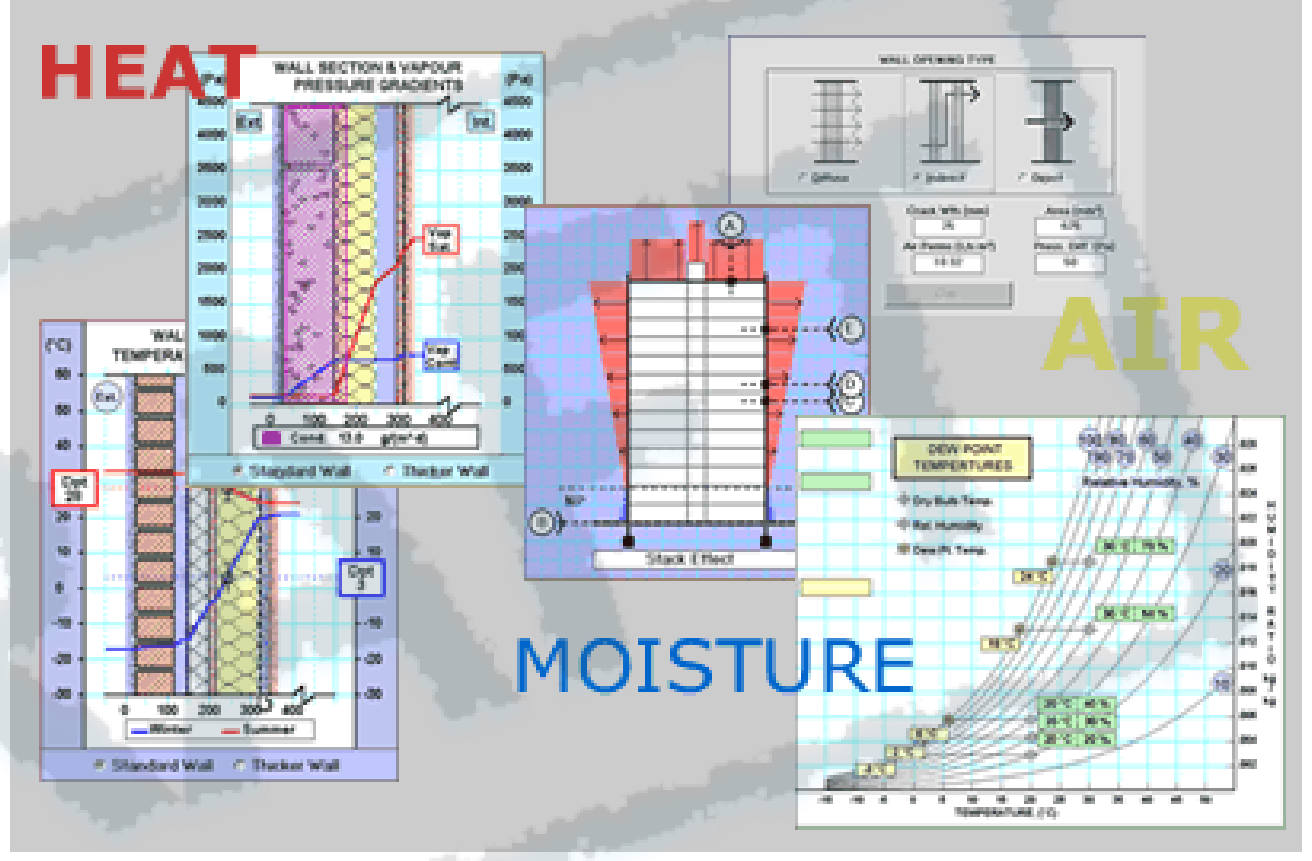

source: www.virtual-north.com 


\section{Simulation tools}

- multi-disciplinary

- problem oriented

- wide(r) scope

- dynamic

- all conditions

- numerical methods (approximate solution of realistic model of reality)

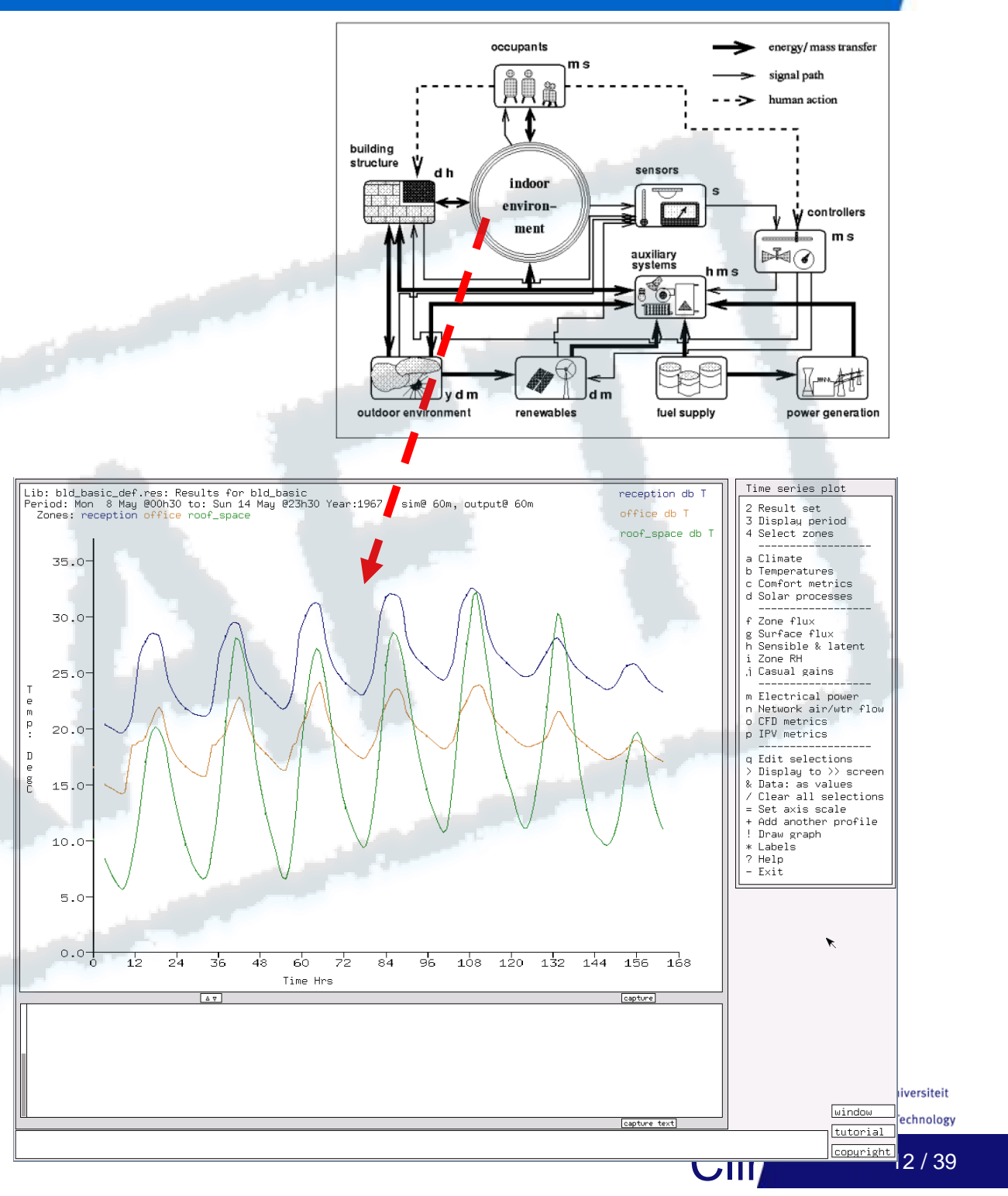


context $>$ building simulation $>$ EPBD $>$ EPBD + simulation $>$ conclusions $>$

\section{What is the difference?}

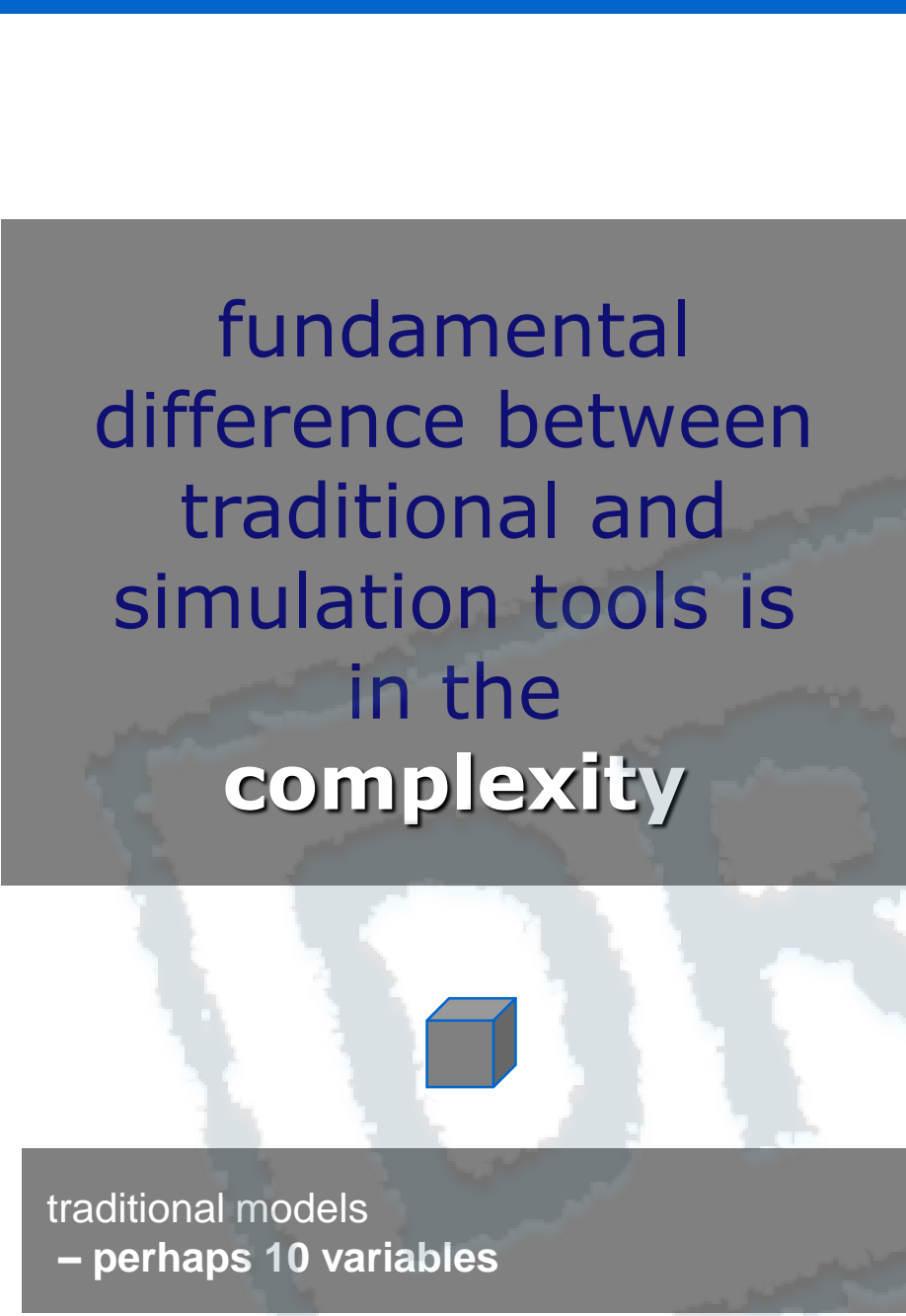

\section{computer simulation \\ - often > 10,000 variables}

therefor much more need for:

- quality assurance

- knowledge / skills

- resources

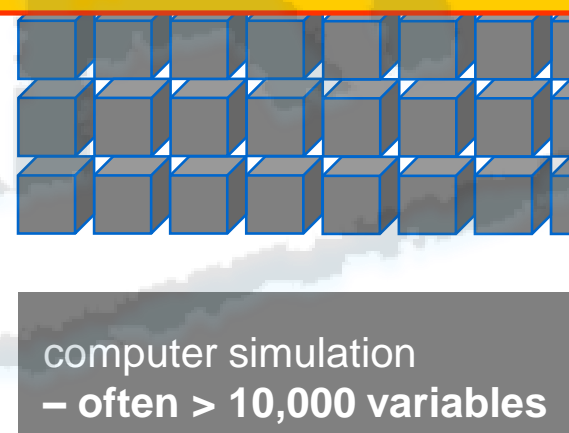




\section{Building simulation user types}

\section{Categories of Innovativeness*}

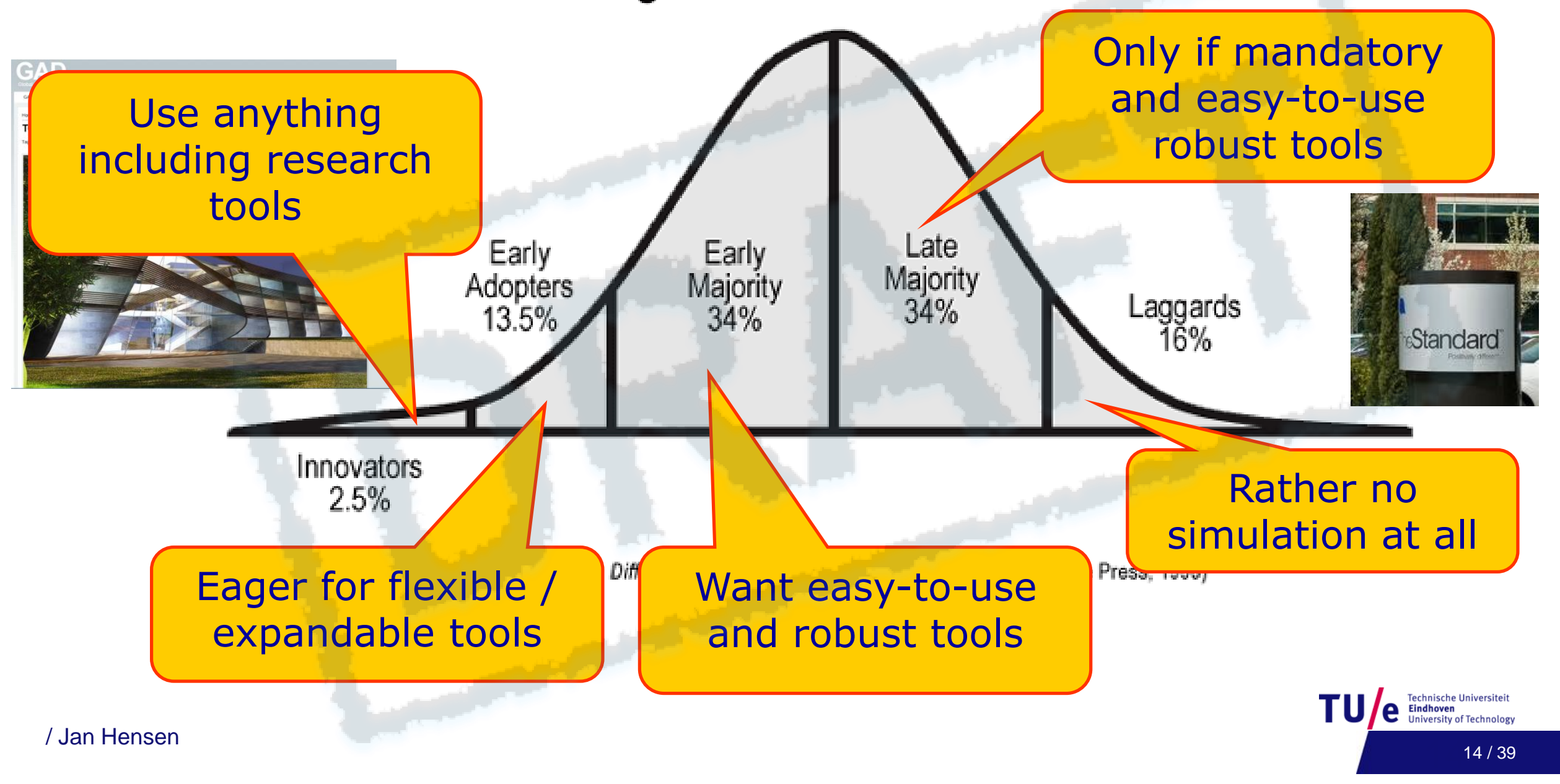




\section{Simulation in the building life-cycle}

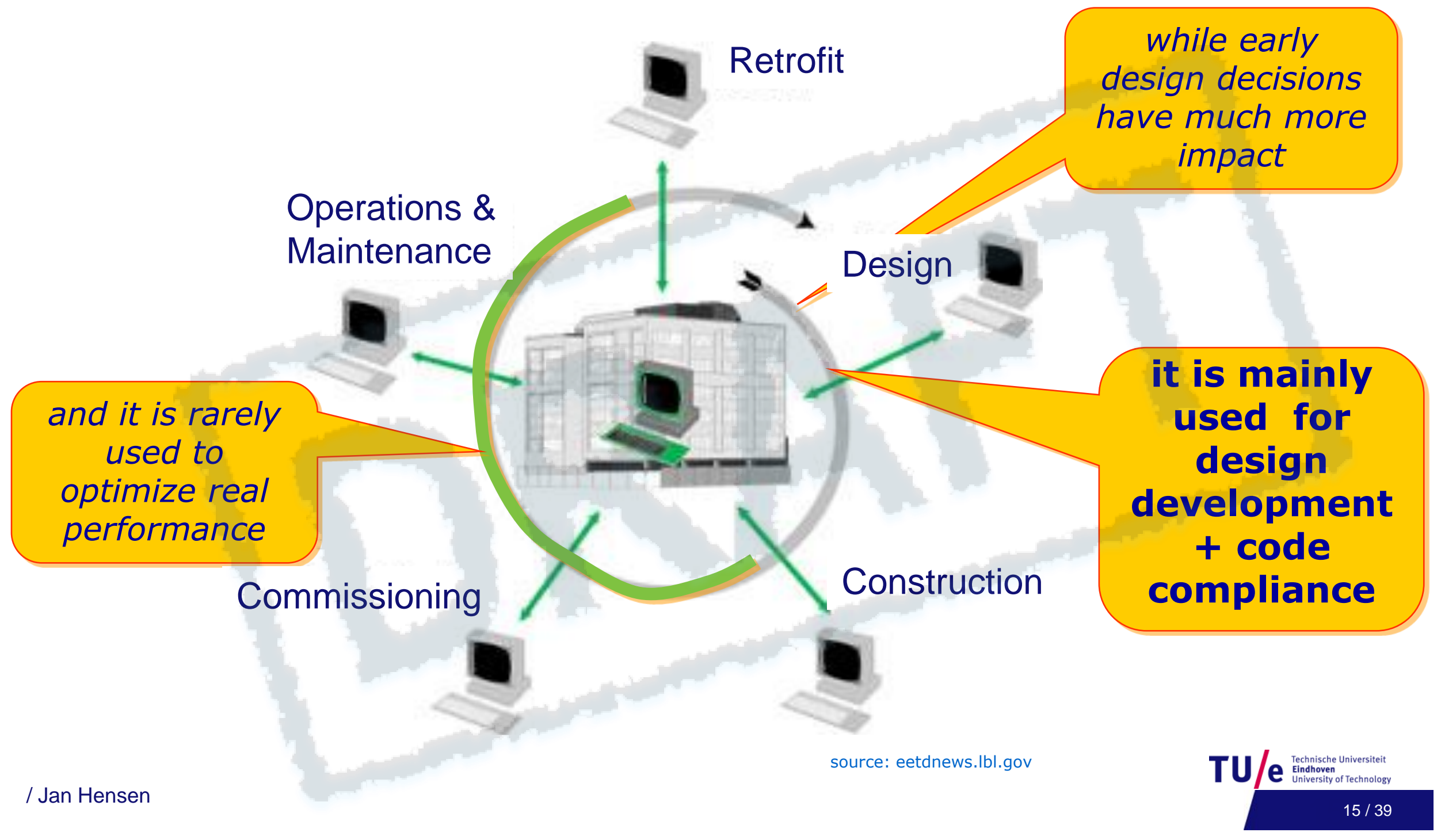




\section{$>$ context $>$ building simulation $>$ EPBD $>$ EPBD + simulation $>$ conclusions $>$ \\ Building simulation challenges}

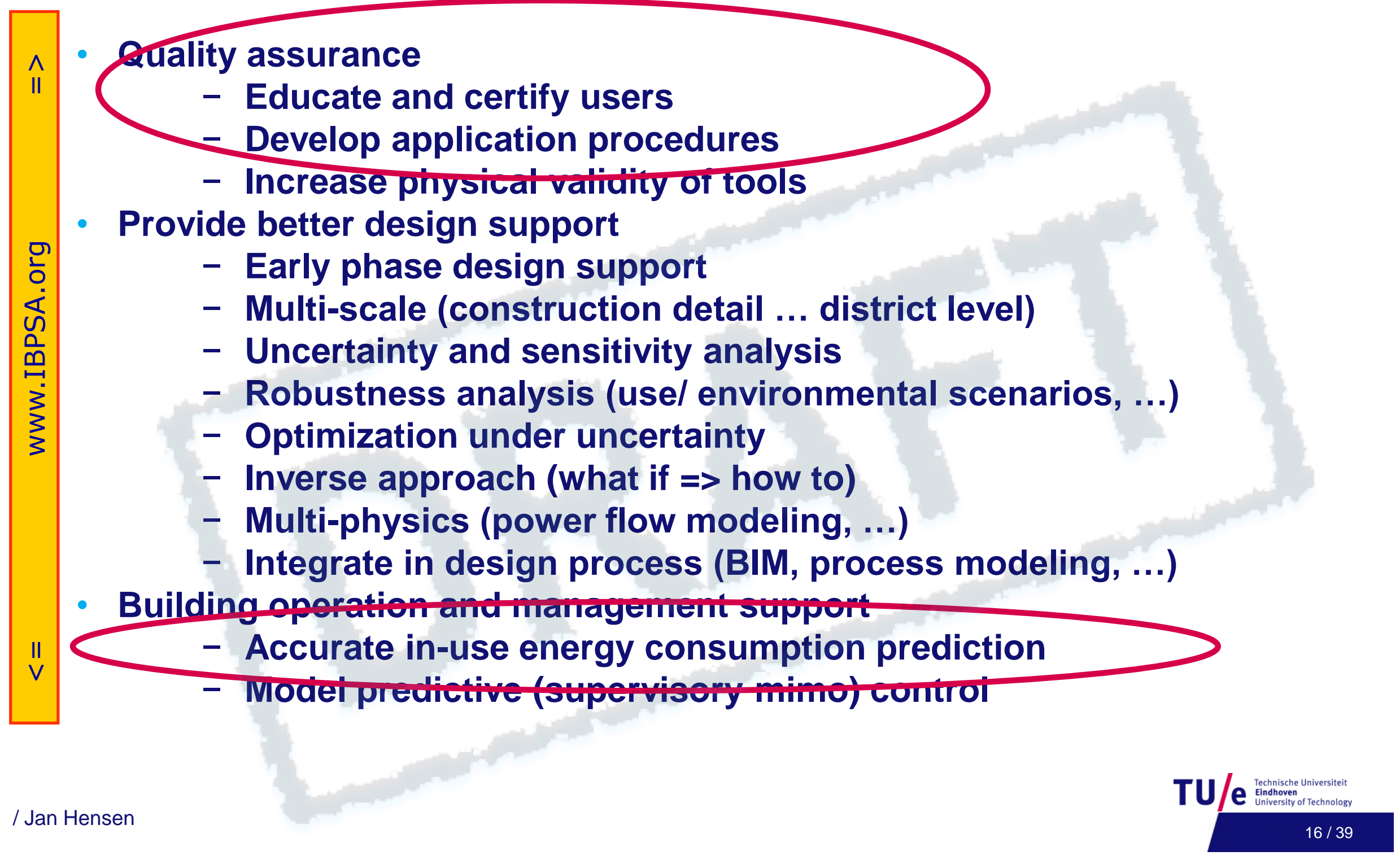




\section{More complex is not always better.....}

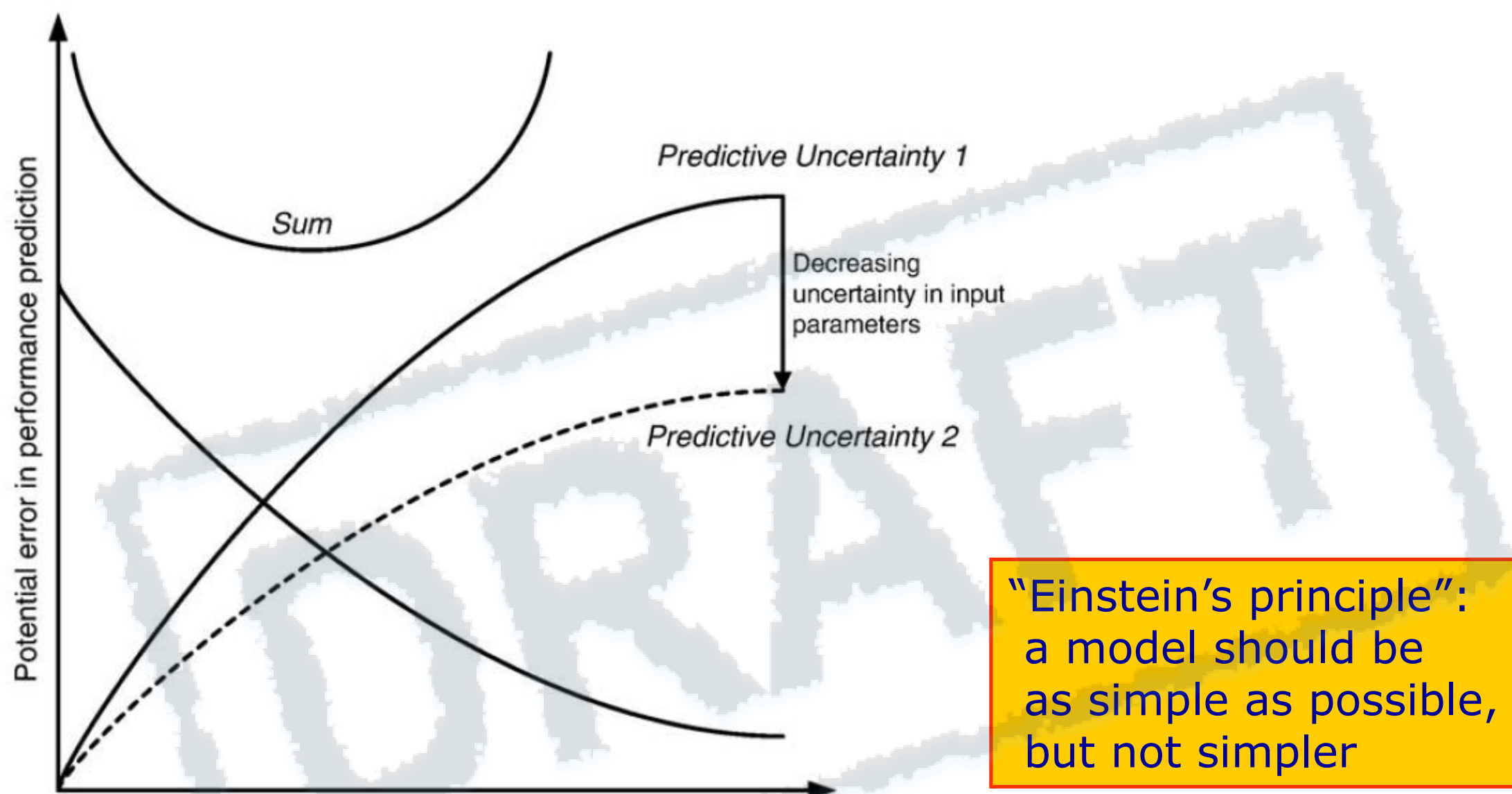

Fig. 3. Model uncertainty vs. complexity. 


\section{Simulation approach - issues}

- Consistency (person to person, program to program)

- Time \& cost (hard- + software, training, project hours)

- Accuracy (but simpler methods have bigger issues)

- Enforcement when "mandatory"

- Maintenance

- Changes in standards

- Bug fixes

- User interface

- Simulation engine 


\section{Quality Assurance (QA)?}

- QA is all about developing confidence in the predictions of simulation tools

- we need to be confident that our models are providing an "accurate" representation of how a building or system will behave in reality

- this is important as we are basing design decisions on the results from simulations

- one of the main mechanisms to improve the quality of a simulation tool is to undertake rigorous validation

- however as we will see later validation is only part of the quality picture 


\section{Validation in Building Simulation}

- the validation of building simulation programs is a challenging field that has existed almost as long as building simulation itself

- extensive validation efforts have been conducted under the auspices of:

- the International Energy Agency (IEA)

- the American Society for Heating Refrigeration and Air-Conditioning Engineers (ASHRAE)

- the European Committee for Standardization (CEN)

- the aim of these efforts was to create methodologies, tests, and standards to verify the accuracy and reliability of building simulation programs 


\section{Validation}

- validation is a means to diagnose internal sources of error in simulation codes

- Judkoff et al. [1983] classify these errors in three groups:

- differences between the actual thermal transfer mechanisms taking place in reality and the simplified model of those physical processes;

- errors or inaccuracies in the mathematical solution of the models; and

- coding errors

R. Judkoff, D. Wortman, B. O'Doherty, and J. Burch. A methodology for validating building energy analysis simulations. Technical Report TR-254-1508, Solar Energy Research Institute, Golden USA, 1983. 


\section{Validation}

- Judkoff and Neymark [1995] proposed three primary validation approaches to check for internal errors:

- analytical verification;

- empirical validation; and

- comparative testing

R. Judkoff and J. Neymark. International Energy Agency Building Energy Simulation Test (BESTEST) and Diagnostic Method. IEA/ECBCS Annex 21 Subtask C and IEA/SHC Task 12 Subtask B Report, 1995. 


\section{Analytical Verification}

- in analytical verification, the program output is compared to a well known analytical solution for a problem that isolates a single heat transfer mechanism

- typically this necessitates very simple boundary conditions

- although analytical verification is limited to simple cases for which analytic solutions are known, it provides an exact standard for comparison

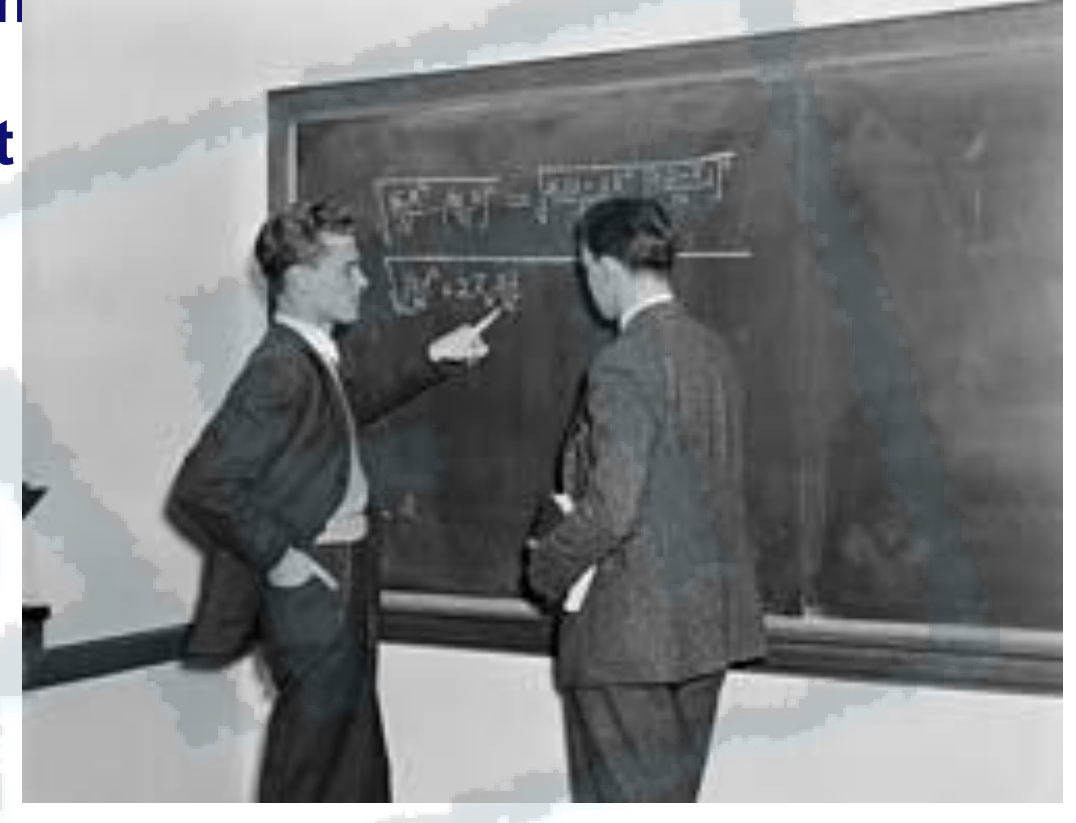




\section{Analytical Test - example}

from Xiao et al. Transient conduction analytical solutions for testing of building energy simulation programs, Building Serv. Eng. Res. Technol. 26,3 (2005) pp. $229 / 247$

- ESP-r and Blast were compared against solutions of the governing thermal diffusivity equation - modelling transient conduction through fabric

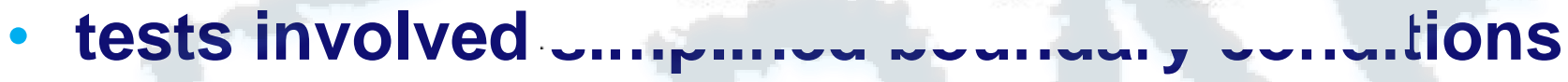

$$
\frac{\partial^{2} T(x, t)}{\partial x^{2}}=\frac{1}{\alpha} \frac{\partial T(x, t)}{\partial t}
$$
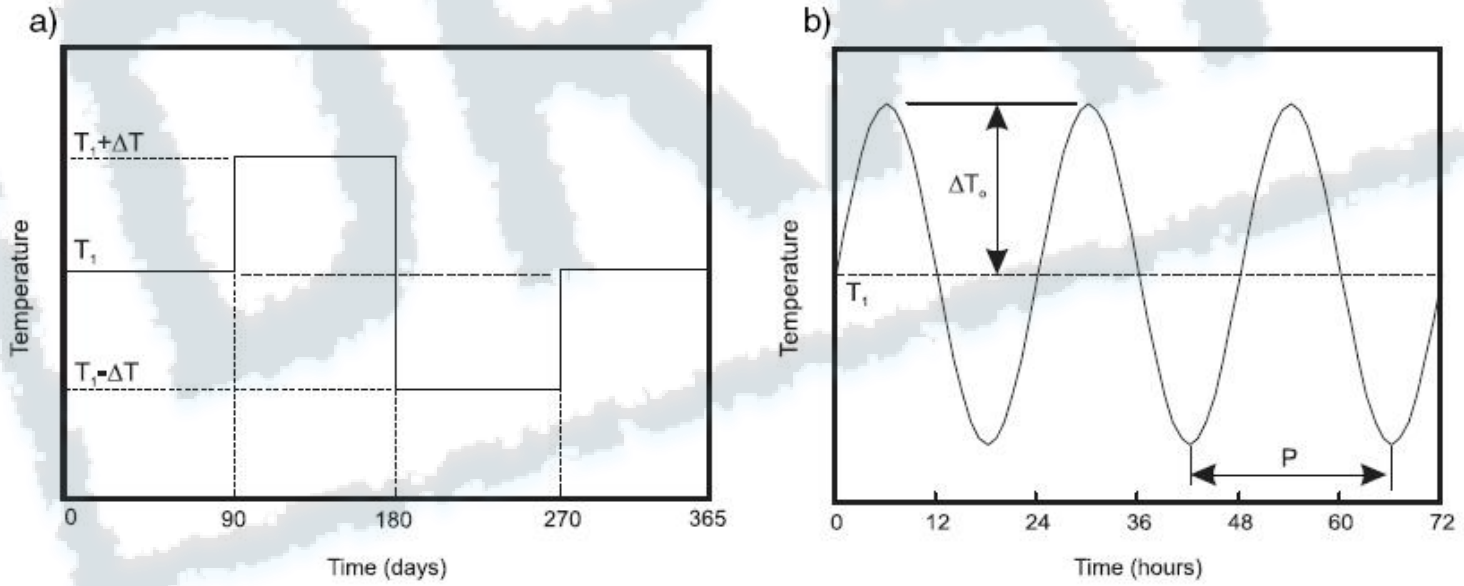


\section{Analytical Tests}

- results from simulation models compared to analytical solutions
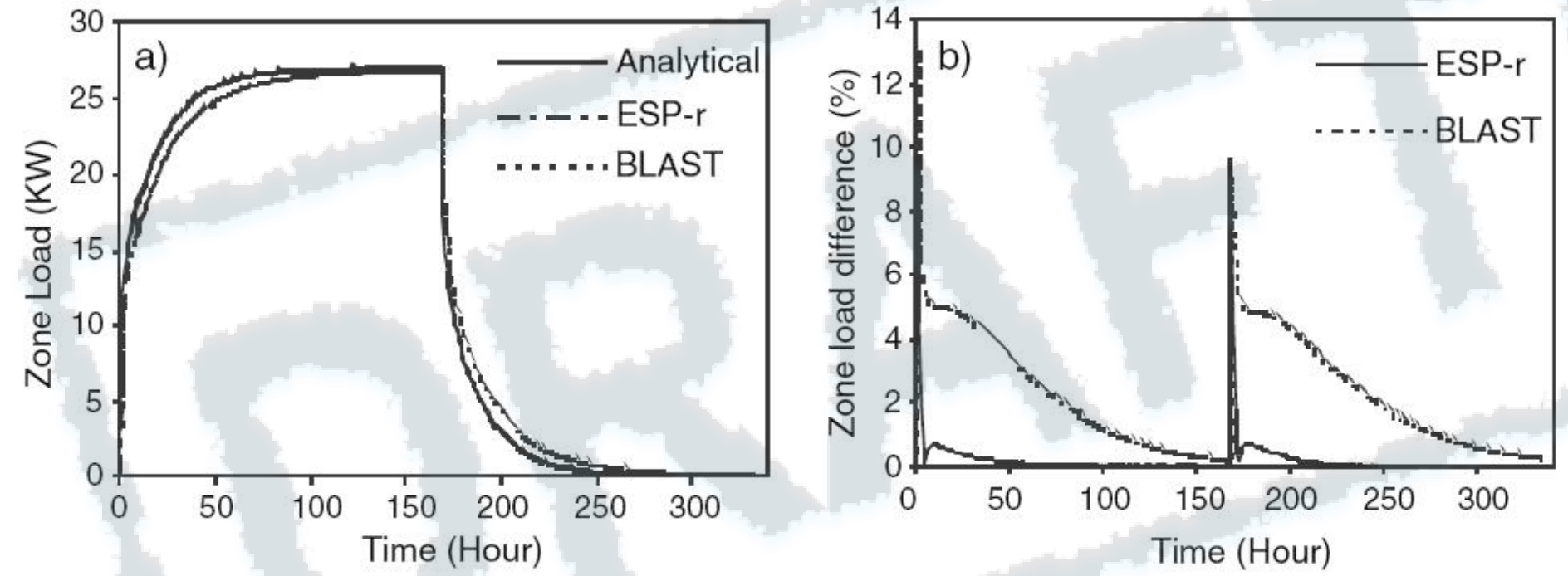

- simulation models used are simple boxes with I Jan Hen basic constructions 


\section{Analytical Tests}

- by their nature analytical tests only exercise a small part of a building simulation model

- the situations modelled need to be simple enough for manual analysis and calculation

- provides a useful indication if the program captures the basic physics of a situation correctly 


\section{Empirical Validation}

- program outputs are compared to monitored data during empirical validation

- the measurements can be made in real buildings, controlled test cells, or in a laboratory

- the design and operation of experiments leading to high-quality data sets is complex and expensive, thus restricting this approach to a limited number of cases

- the characterization of some of the more complex physical processes treated by building simulation programs (such as heat transfer with the ground, infiltration, indoor air motion, and convection) is often excluded due to measurement difficulties and uncertainty

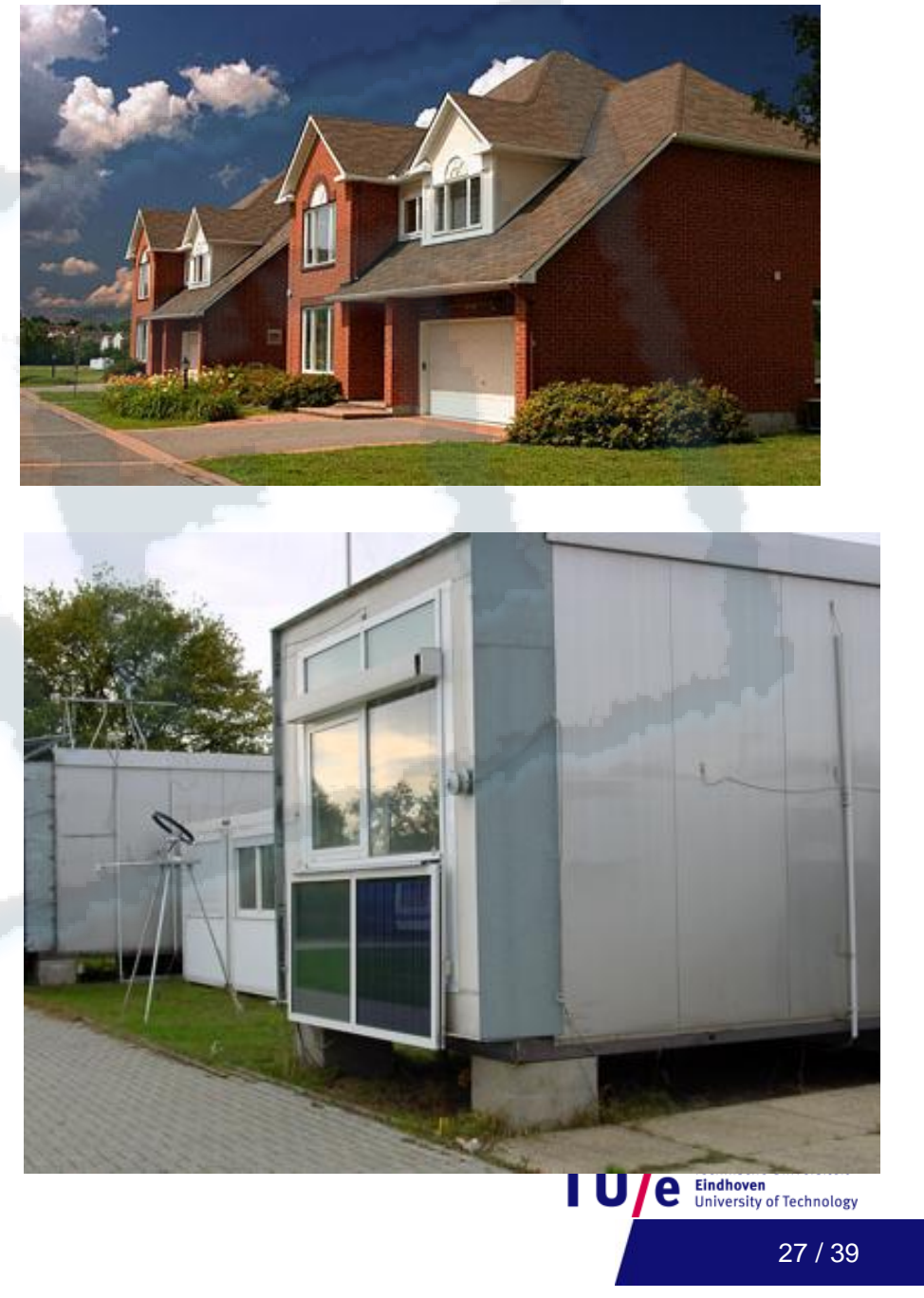




\section{Empirical Validation - example}

Just testing two of the many component models in a simulation software: dynamics of a radiator represented by

\section{a 2 node or} an 8 node model Source: Hensen 1991

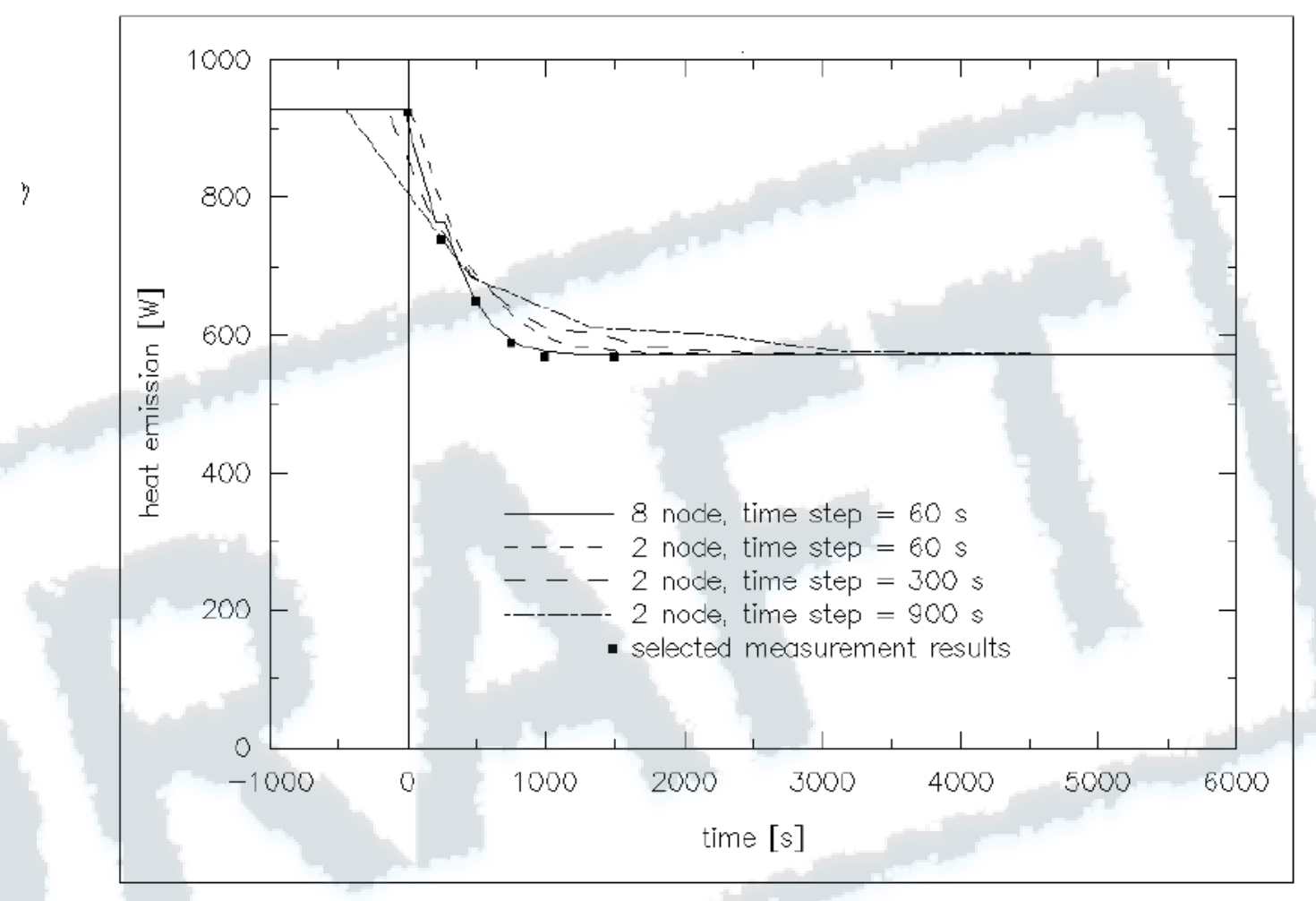

Figure 6.4 Radiator heat emission following a step change in inlet water temperature $\left(91.0->70.4^{\circ} \mathrm{C}\right)$, as computed by bps with the two radiator models using different simulation time-steps. To the right are measured (dots) and computed $(+)$ results as presented by Crommelin and Ham (1982). Some measurement results were copied to the left graph. 


\section{Empirical Validation}

- provides a rigorous test of performance

- however experiments need to be designed and undertaken specifically for the purposes of collection of validation data

- ....otherwise data is often not useful for validation

- expensive and very time consuming process 


\section{Inter-Model Comparison}

- a program is compared to itself or other programs during comparative testing

- this includes both sensitivity testing ar inter-model comparisons

- this approach enables inexpensive comparisons at many levels of complexity

- however, in practice the difficulties in equivalencing program inputs and outputs can lead to significant

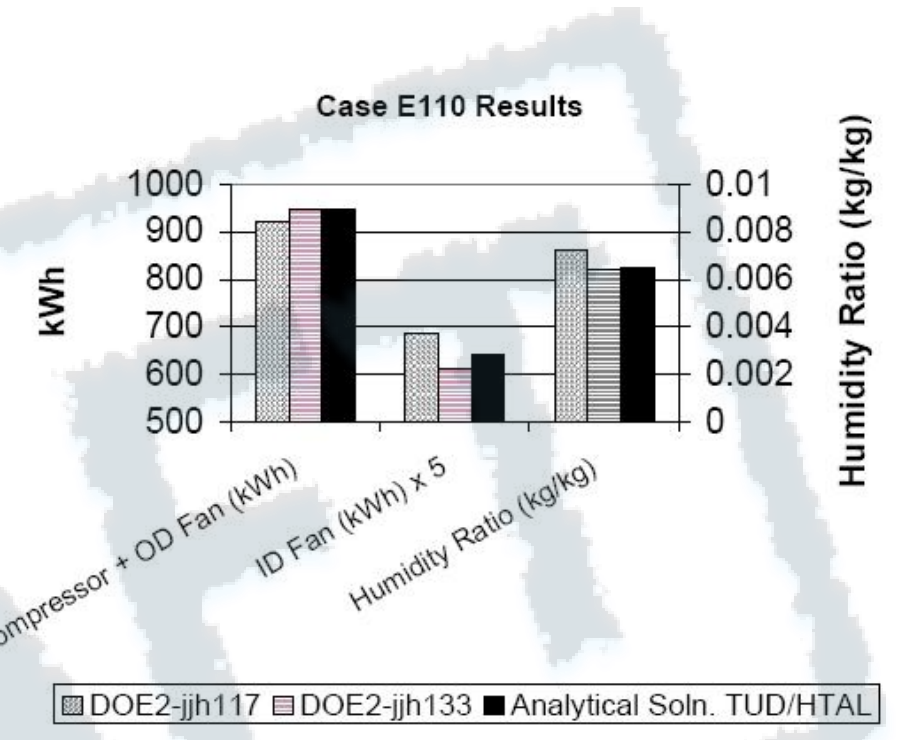
uncertainty in performing inter-model comparisons

- comparative testing also provides no absolute measurement of program accuracy; while different programs may make similar predictions, all of these predictions may be incorrect

$$
\text { 西 }
$$




\section{BESTEST $\Rightarrow$ ASHRAE SMOT 140}

- Intermodel comparative test

- Comparison with several other tools which are usually better familiar to the validators (ESP-r, TRNSYS, BLAST, DOE2...)

- Well defined cases

- Cases progress systematically from the extreme simple to the relatively realistic

- Specific problem detection - diagnosis 


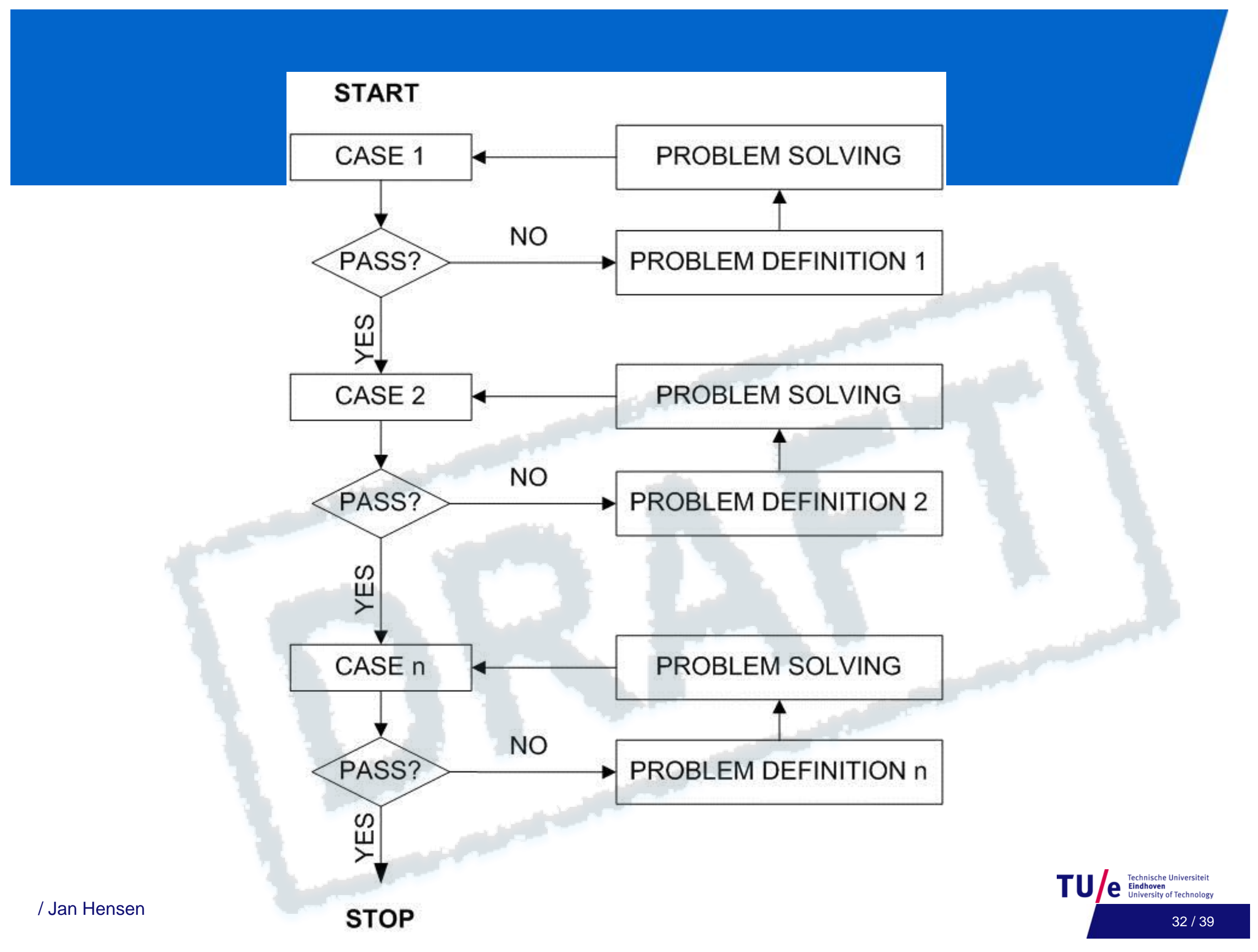




\section{Example - Case 600}

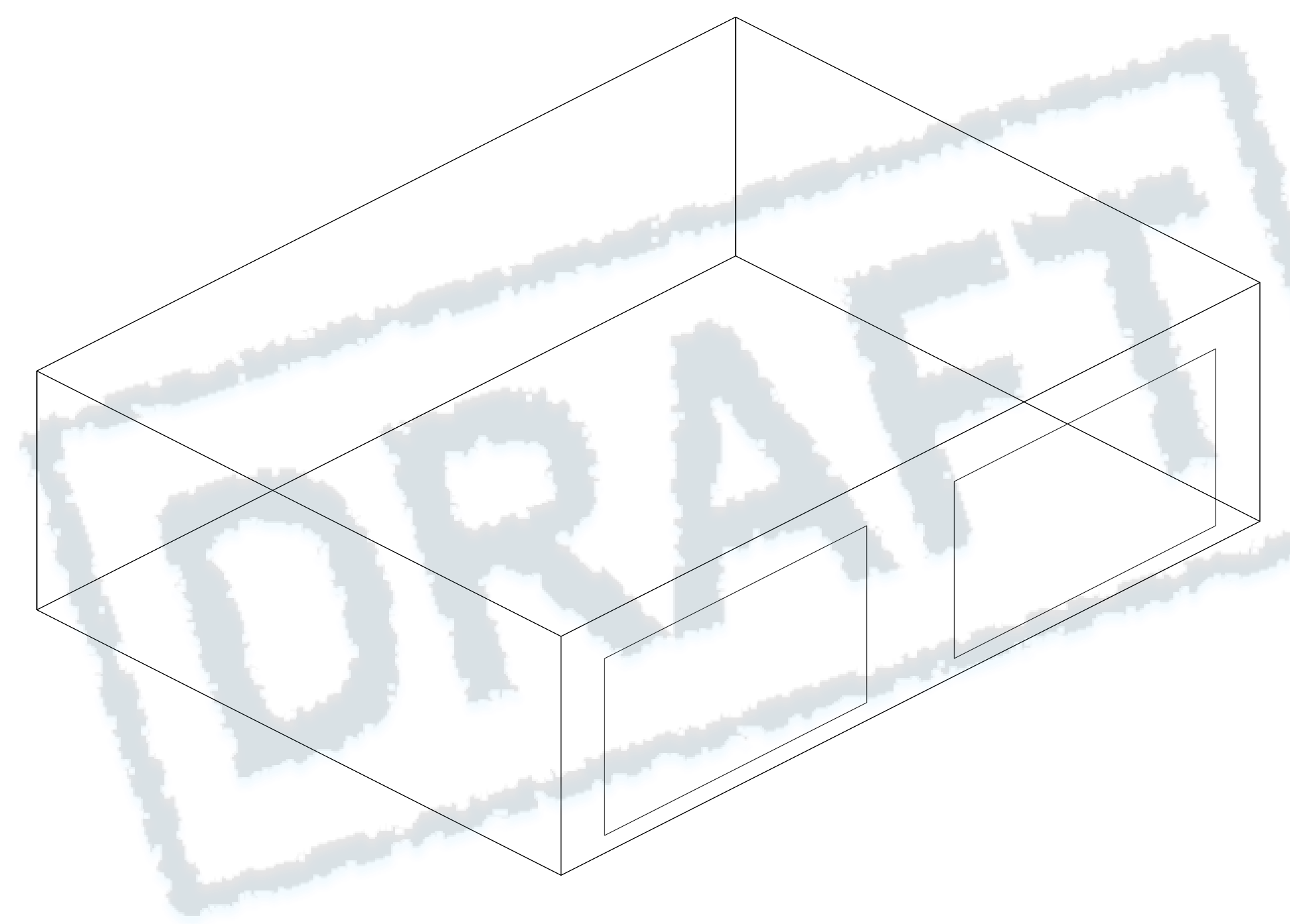




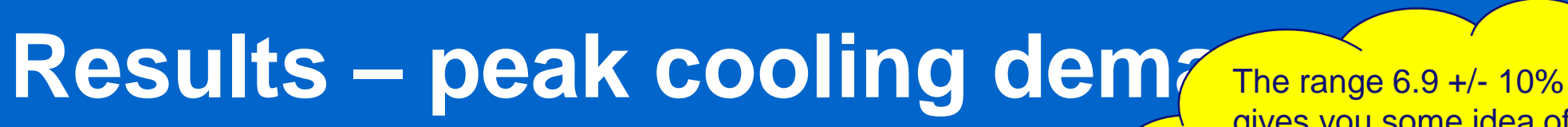 \\ gives you some idea of}

"normal" uncertainty - and

this is for a really very simple building, with no definition uncertainty

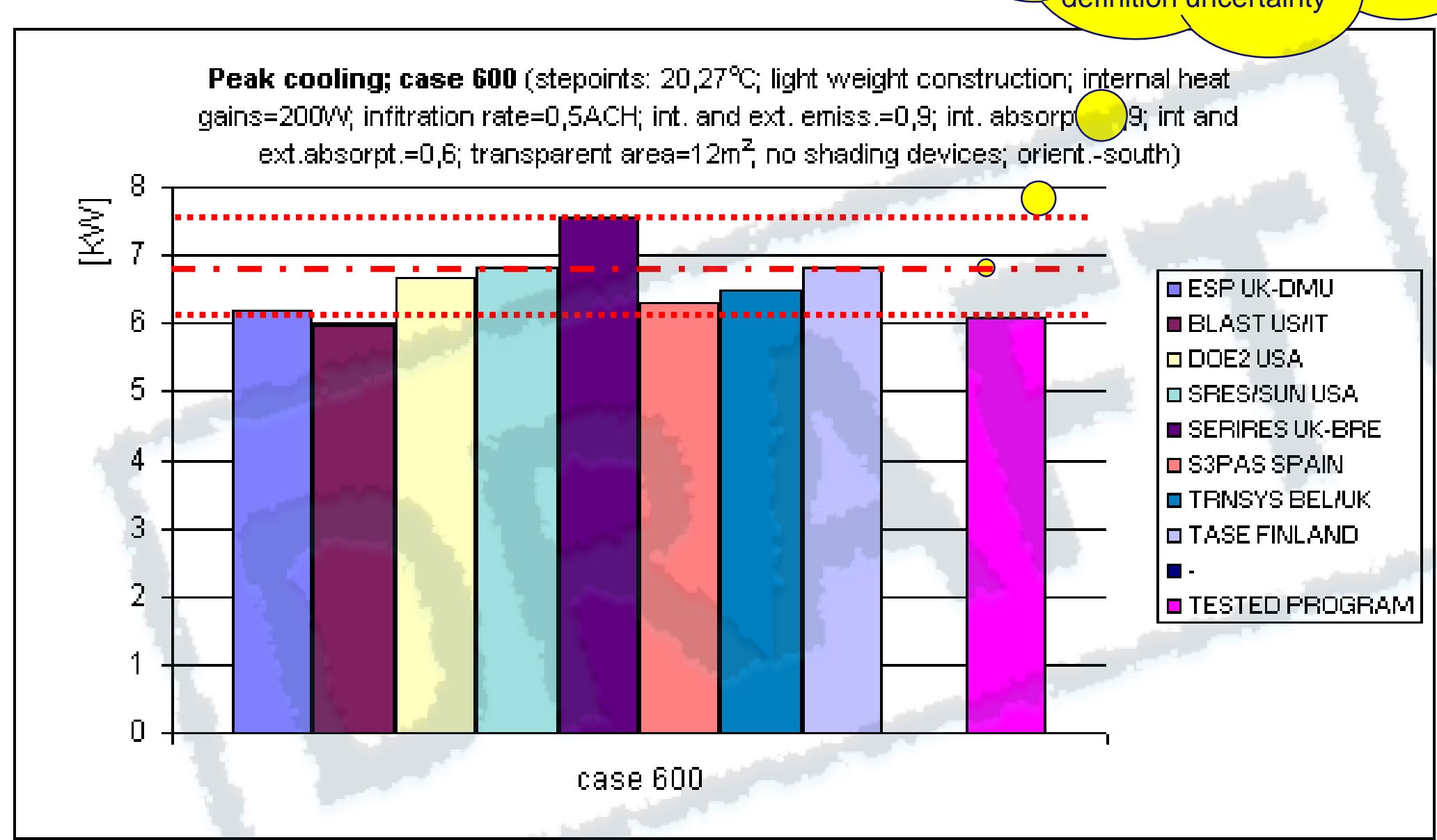




\section{Results - annual cooling [MWh]}

Enegry consumption for cooling; case 270 (stepoints: 20 construction; internal heat gains $=0 \mathrm{~W}$, infitration rate $=0 \mathrm{ACH}$; int. a absorpt. $=0,9 ;$ ext.absorpt. $=0,1$; transparent area $=12 \mathrm{~m}^{2}$, no shading

BESTEST was used to find out why this software performs "out of range"; for details see source

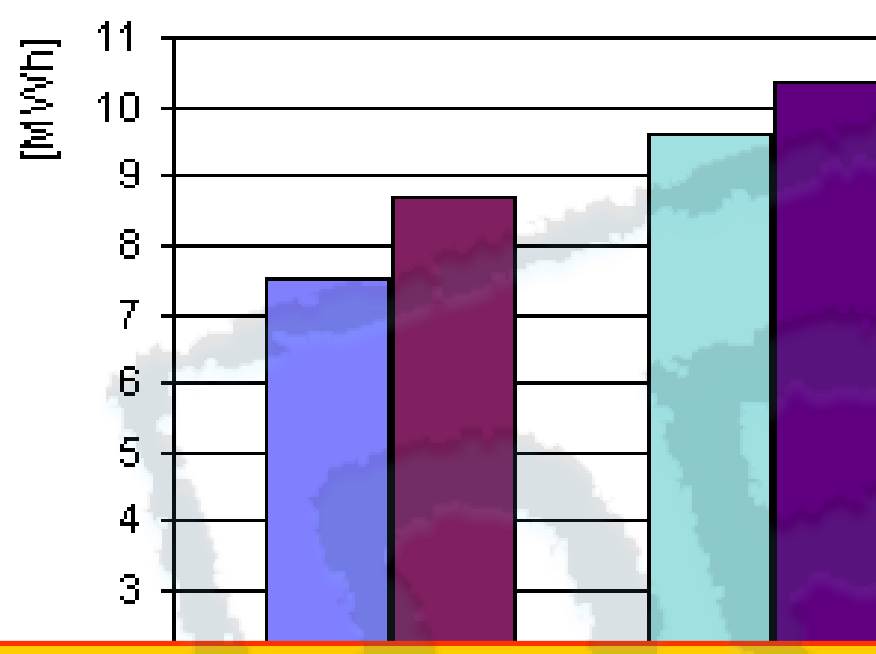

Although a program is commercially available, that does not necessarily guarantee its quality Make sure to use software that has passed BESTEST, ASHRAE SMOT 140 or similar

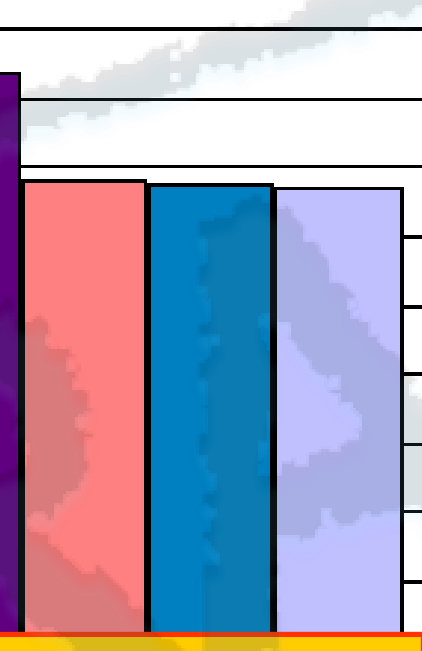

SP UK-DMU BLAST USHT 口DOE2 USA 口 SRESISUN USA ם SERIRES UK-BRE 口S3PAS SPAIN 口 TRNSYS BELIUK 口TASE FINLAND a -
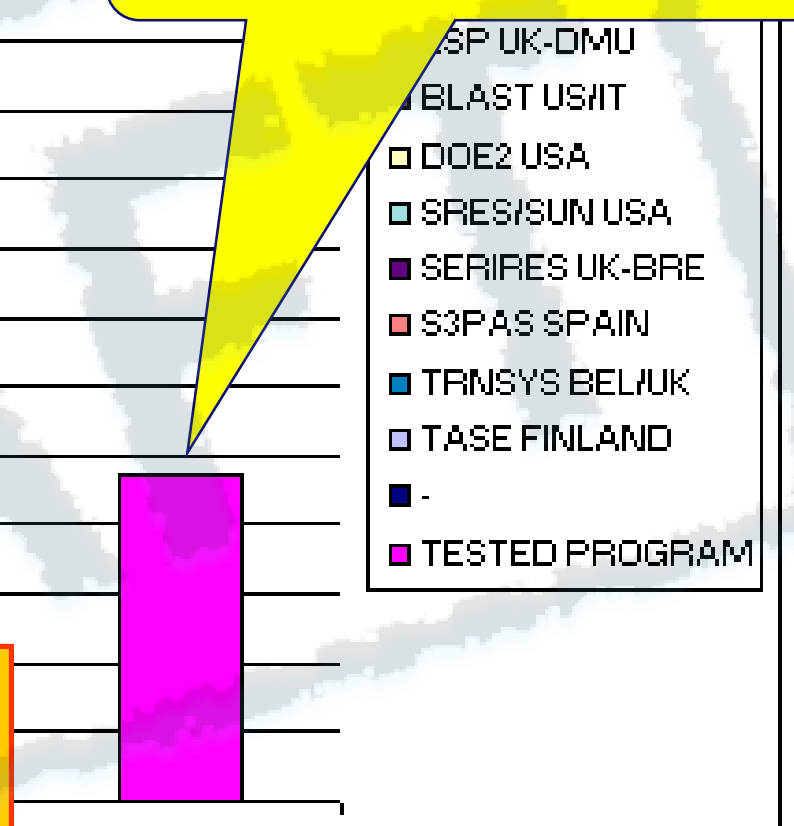


\section{Relative differences - better?}

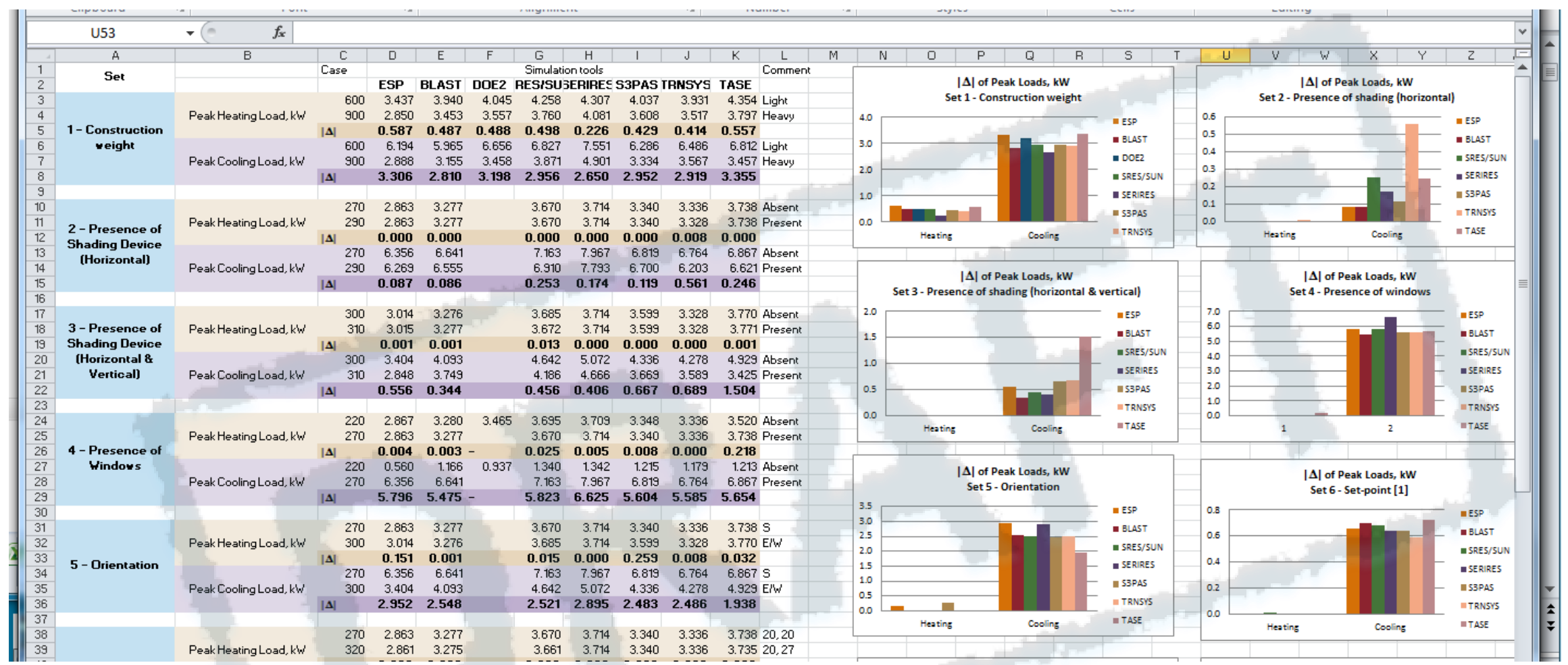




\section{Validation \& Verification - summary}

\begin{tabular}{|l|l|l|}
\hline Method & Pros & Cons \\
\hline Comparative & $\begin{array}{l}\text { No input problem } \\
\text { Any level of complexity } \\
\text { Inexpensive \& quick }\end{array}$ & No truth standard \\
\hline Analytical & $\begin{array}{l}\text { No input uncertainty } \\
\text { Exact truth standard } \\
\text { Inexpensive }\end{array}$ & No test of model \\
\hline Empirical & $\begin{array}{l}\text { Approximate "truth" } \\
\text { Any level of complexity }\end{array}$ & Expensive \& time-consuming \\
\hline & $\begin{array}{l}\text { Anta uncertainty } \\
\text { Expes }\end{array}$ \\
\hline
\end{tabular}




\section{External Sources of Error}

- finally .... the major sources of error in modelling ....

- the user

- setting up the model, model abstraction, interpretation of data, data input, results interpretation, etc

- Guyon et al. (1997) showed variations of $40 \%$ in results from the same model but with different users

- quality can be improved by providing adequate training to the user

- and ensuring support, supervision and expertise are available

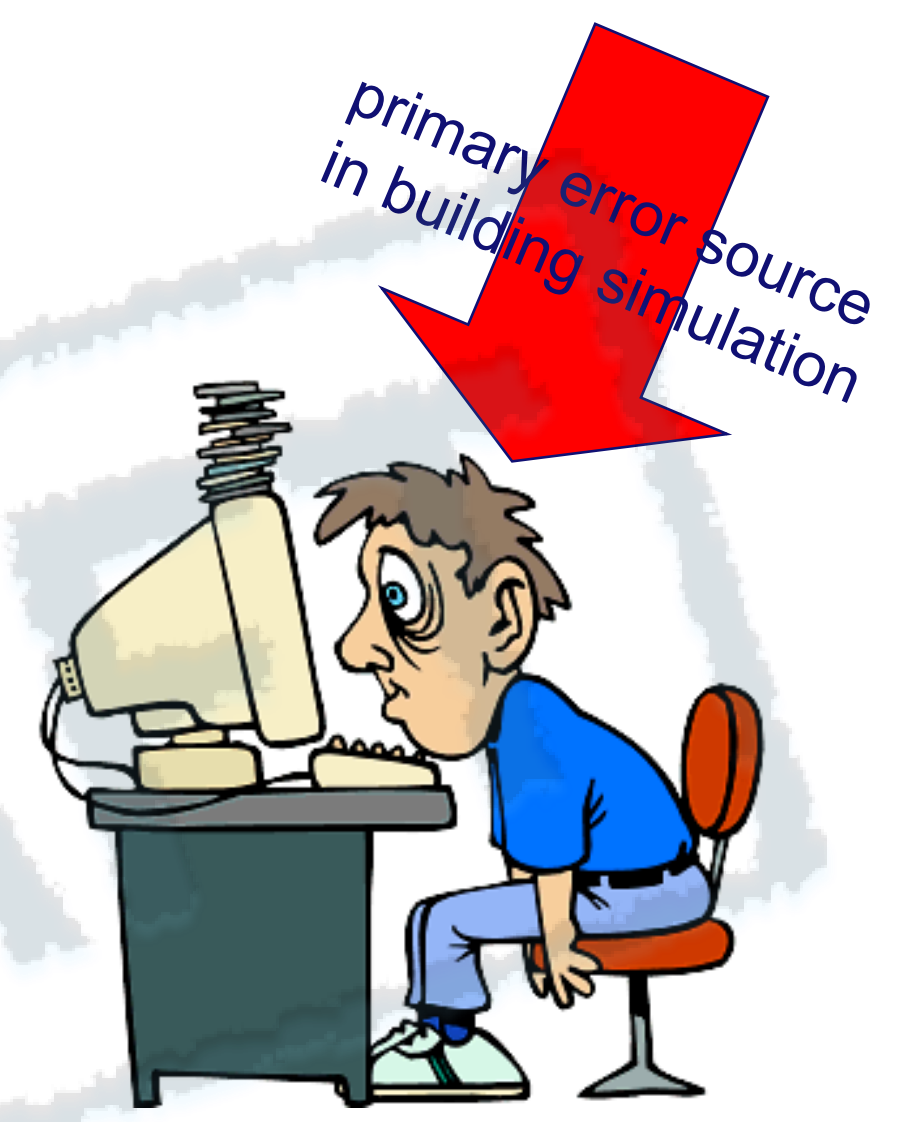

Guyon G, The role of the user in results obtained from simulation software program, in proc. BS'97 The International Building Simulation Conference, Prague, 1997 


\section{Quality Essentials - in summary}

- Engineering essentials:

- Knowledge and understanding of fundamentals and basic principles

- Being able to creatively solve real world problems

- By knowing which tools to use, when, why and how

- Simulation $=$ discipline $(>\mathbf{s} / \mathbf{w})$

- Quality assurance through:

- Appropriate level of resolution and complexity

- Calibration of validated software

- (Design) application methodology 


\section{Sources of uncertainty}

- Physical uncertainty

- Occupant behaviour

- Scenario uncertainty

- ....

- .... 


\section{"Uncertainty analysis" (1984)}
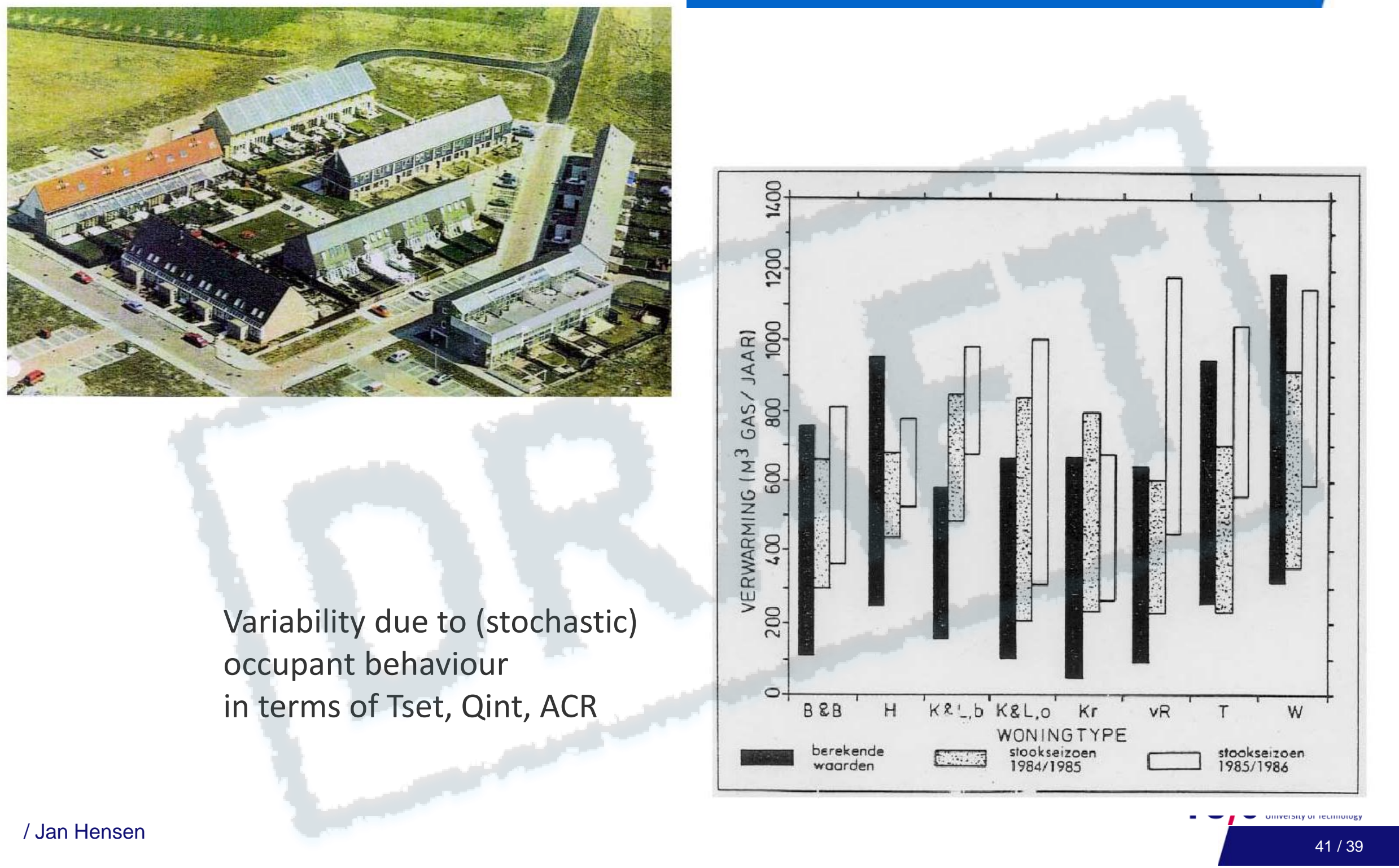


\section{Uncertainty \& sensitivity analysis}

Variability due to physical parameter uncertainty

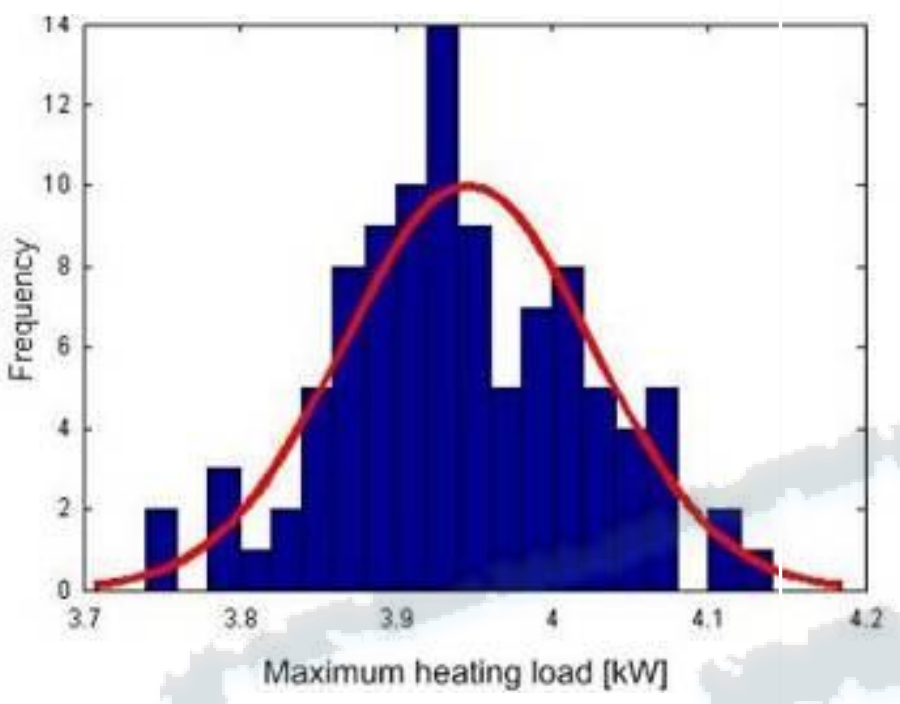

Sensitivity of design parameter on uncertainty of cooling demand

Glass Perce $50-100 \%$

Gass syster therm. Perf. low -high

Build. lass 110 - 295kg/hn

Floor rea 48-72na

Wall InsL $2.5-4.01 \mathrm{KK} / W$

Roof InsL $2.5-4.013 \mathrm{~K} / \mathrm{W}$

$\begin{array}{lllll}-0.8 & -0.4 & 0.0 & 0.4 & 0.8\end{array}$

Stand. regression coefficient (SRC)

Design options "Examples"

Integrated design concept ${ }^{4}$
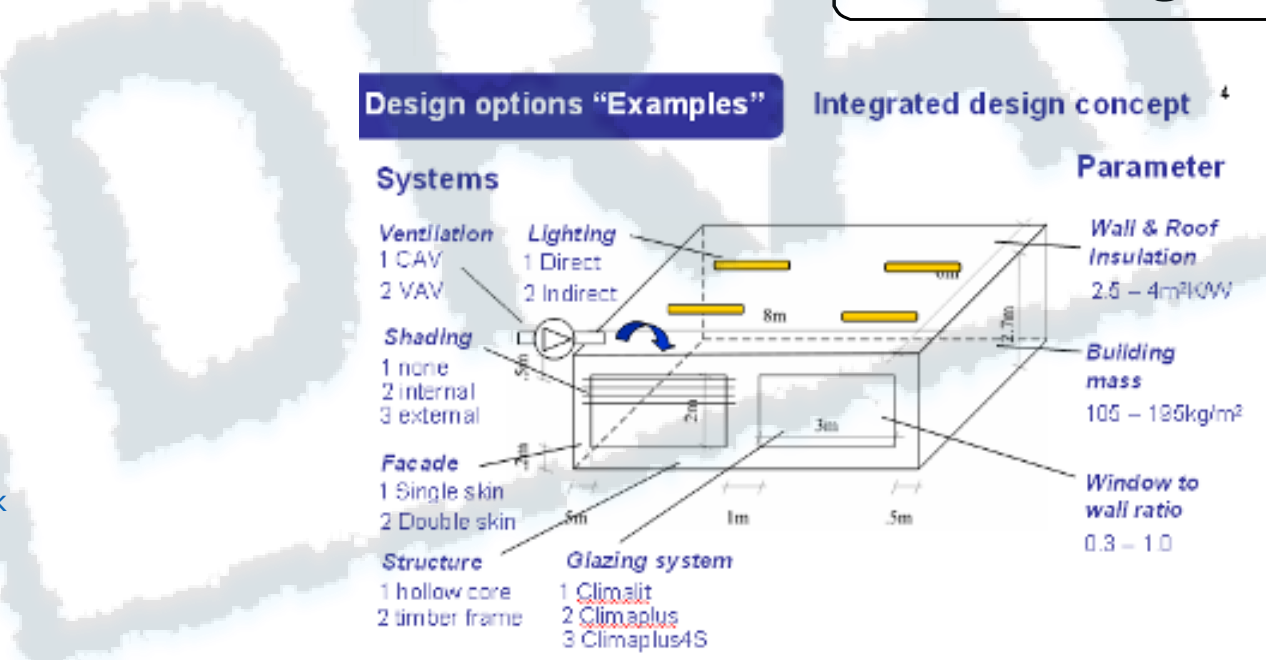

k

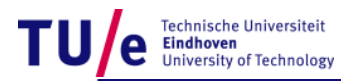




\section{Uncertainty \& robustness analysis}
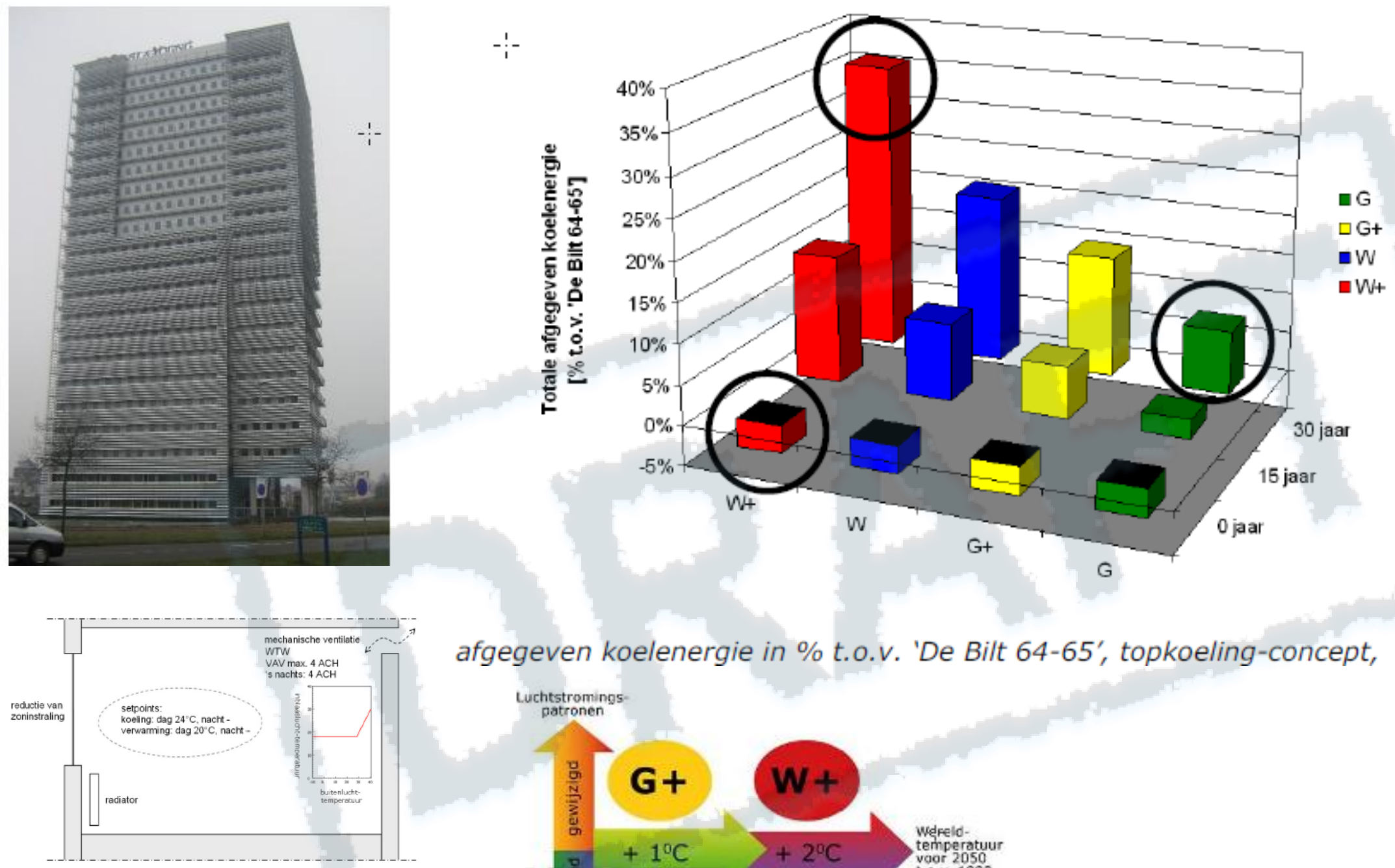

afgegeven koelenergie in \% t.o.v. 'De Bilt 64-65', topkoeling-concept,

Source: Janneke Evers / Jan Hensen

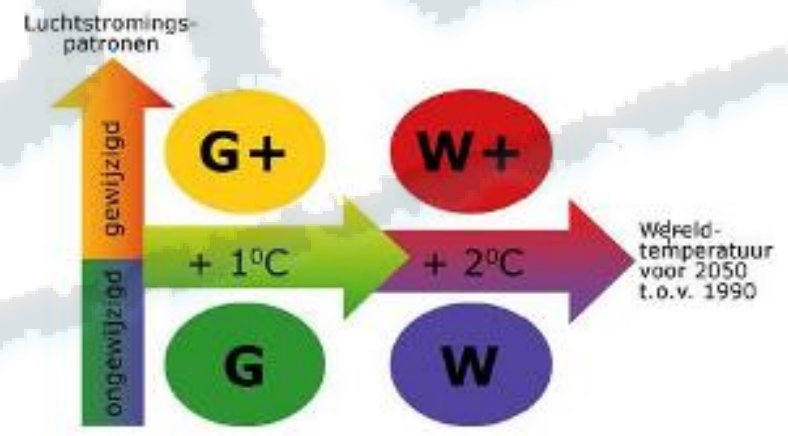

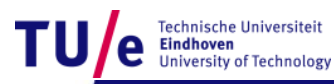




\section{Uncertainty \& robustness analysis}
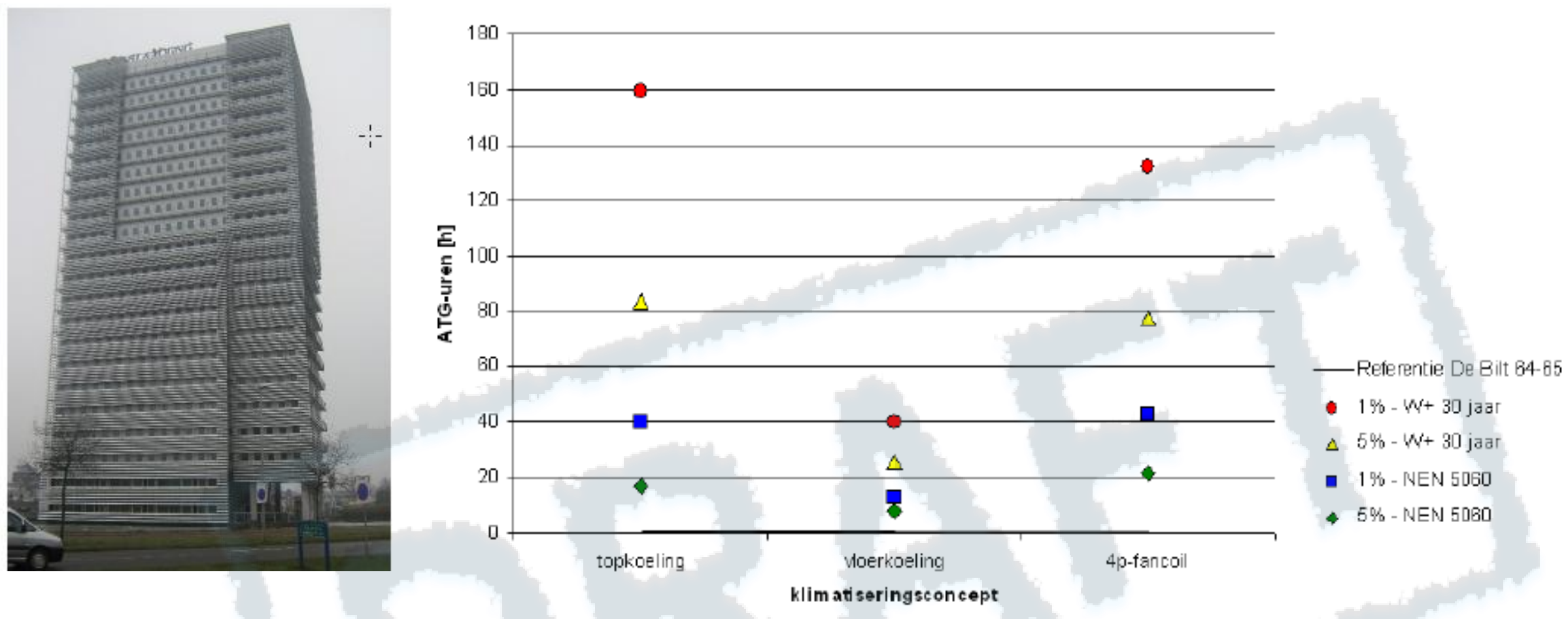

Fig. 6.4: Vergelijking van 3 klimatiseringsconcepten, ATG-uren, 'klimaatbestanden voor de toekomst', installatie gedimensioneerd op ATG-klasse B met 'De Bilt 64-65'

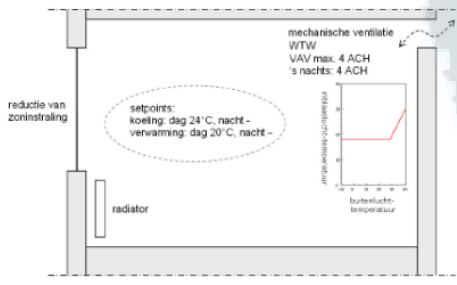

/ Jan Hensen

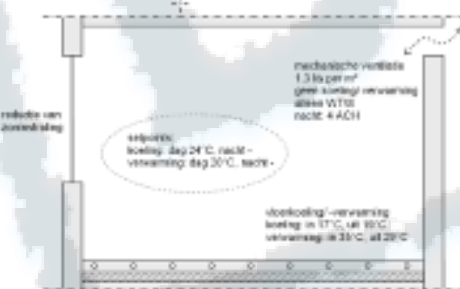

Source: Janneke Evers

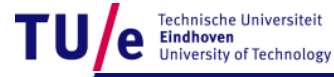




\section{Simulation "user accuracy"}

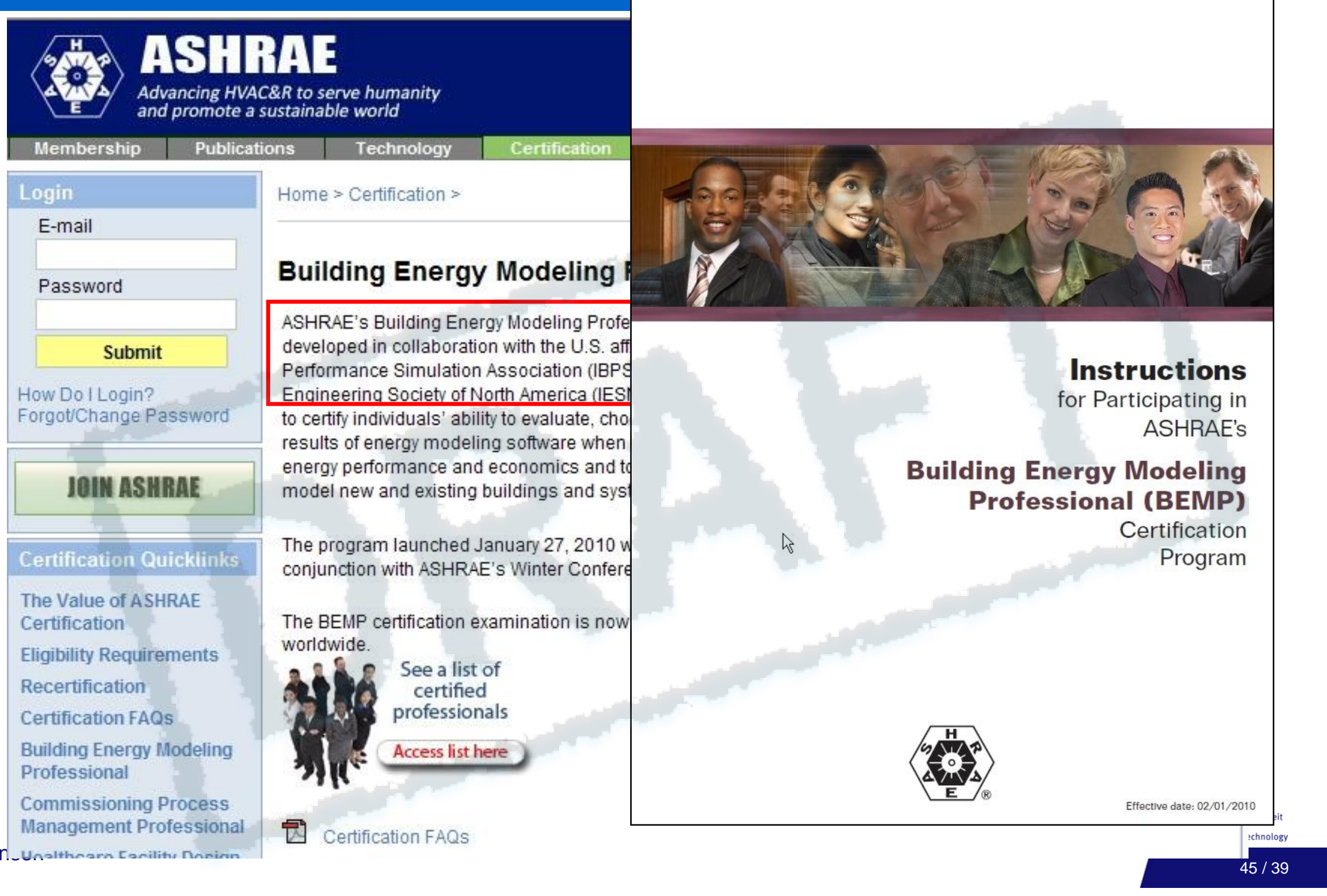




\section{Quality assurance - summary}

- Engineering essentials:

$\circ$ Knowledge and understanding of fundamentals and basic principles

- Being able to creatively solve real world problems

- By knowing which tools to use, when, why and how

- Simulation = discipline $(>\mathbf{s} / \mathbf{w})$

- Quality assurance through:

- Appropriate level of resolution and complexity

- Calibration of validated software

- (Design) application methodology

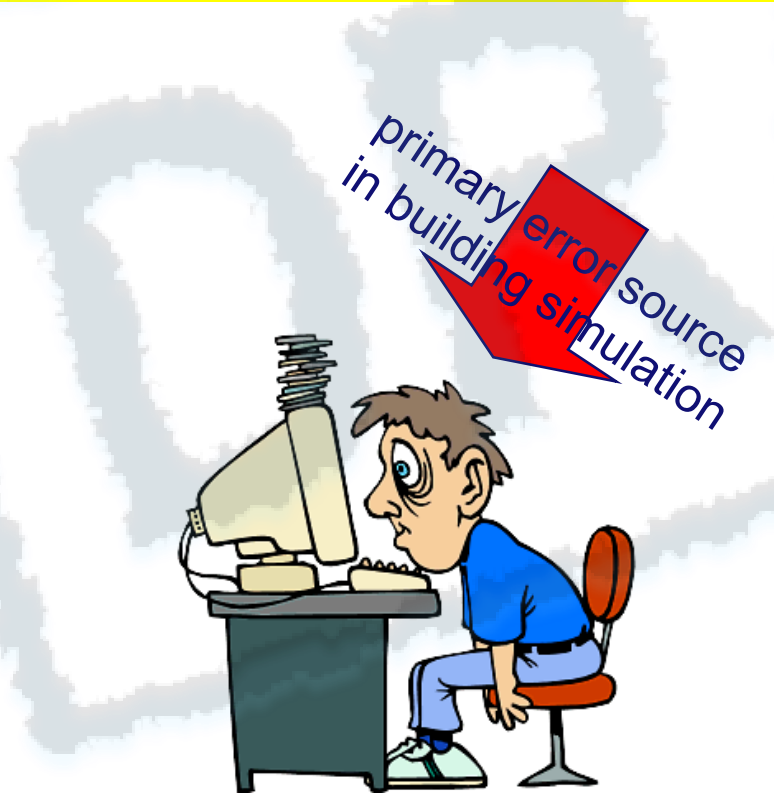




\section{Conclusions}

- Main challenges: existing buildings, O\&M, IEQ

- Simulation is a very promising technology for addressing major technical "sustainable building" challenges towards 2020 and beyond

- Simulation still needs many improvements, e.g.:

- Quality assurance (tools, users \& use)

- Usefulness and integration in/ for performance based design and operation of buildings

- Opportunities for cooperation REHVA / IBPSA

- R\&D, Best Practice Examples, Guidebooks, Courses, Tool Accreditation, User Certification, ........ 


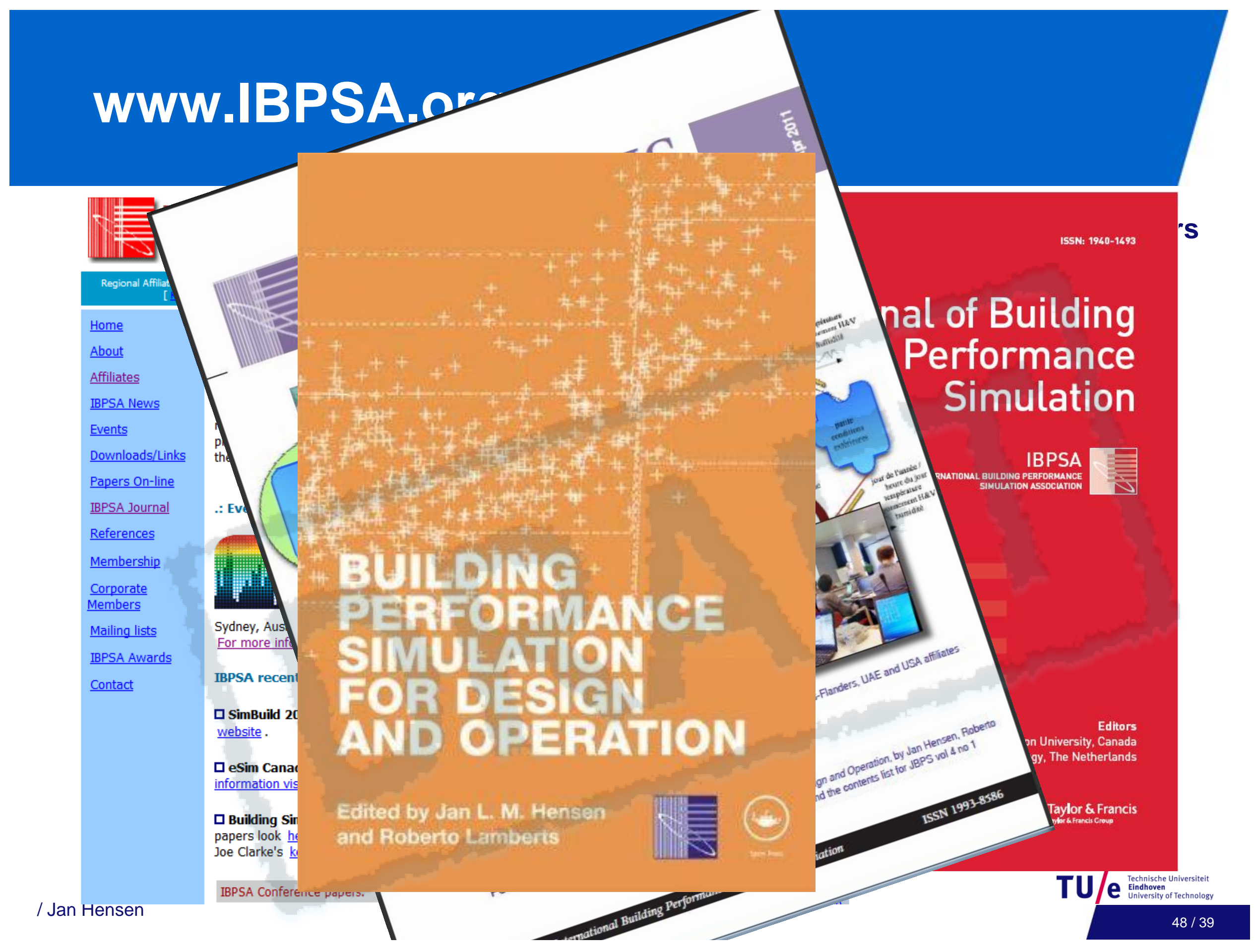

